\title{
La narrativa garciamarquiana como interpretación jurídica de la realidad
}

The Garciamarquian narrative as a legal
interpretation of reality

A narrativa garciamarquiana como interpretação jurídica da realidade

Interprétation juridique de la réalité dans le récit de Garcia Marquez

Andrés Pérez Velasco ${ }^{1}$ Universidad Externado, Colombia

Revista Derechos en Acción

Año 3/No 9 Primavera 2018, 195-250

DOl: https://doi.org/10.24215/25251678e219

ORCID: https://orcid.org/0000-0002-2879-4311

Recibido: 19/07/2018

Recibido con modificaciones: 28/09/2018

Aprobado: 01/11/2018

Resumen: El examen del maridaje entre derecho y literatura empezó hace un tiempo relativamente corto, circunstancia que no deja de ser notable, si se considera la pluralidad de ejemplos que demuestran que el vínculo entre ambas disciplinas es más que centenario. Crónica de una muerte anunciada y El coronel no tiene quien le escriba, narrativas de Gabriel García Márquez, constituyen notables ejemplos de la manera como el derecho se expresa en la literatura, la que a su vez propone una nueva lectura de este tipo de contenido y permite razonar de maneras novedosas el universo de lo que el hombre del común denomina, no sin cierta reticencia, lo legal. El estudio de estas dos expresiones de la narrativa garciamarquiana, entendidas como interpretaciones jurídicas de la realidad, constituye un campo fértil para precisar, por una parte el

\footnotetext{
1 Abogado, Universidad Externado de Colombia. Especialista en Derecho Constitucional, Universidad Nacional de Colombia. Máster en Estudis Avanzados en Literatura Española e Hispanoamericana. Estudiante del Programa de Doctorado de la Universidad de Buenos Aires.
} 
análisis de las lesiones que causan los derechos en suspenso en el tejido social; y por la otra, la degradación de la justicia cuando esta brilla por su ausencia en cualquier esquina del caribe latinoamericano.

Palabras clave: Gabriel García Márquez, Crónica de una muerte anunciada, El coronel no tiene quien le escriba, derecho, literatura.

Abstract: The examination of the marriage between law and literature began a relatively short time ago, a circumstance that does not cease to be remarkable if one considers the plurality of examples that demonstrate that the link between the two disciplines is more than a centenary. Crónica de una muerte anunciada y El coronel no tiene quien le escriba, narratives by Gabriel García Márquez, are notable examples of the way law is expressed in literature, which in turn proposes a new reading of this type of content and allows reasoning in new ways the universe of what the common man calls, not without a certain reluctance, the legal. The study of these two expressions of Garciamarquian narrative, understood as legal interpretations of reality, constitutes a fertile field for specifying, on the one hand, the analysis of the injuries caused by suspended rights in the social fabric; and on the other, the degradation of justice when it shines through its absence in any corner of the Latin American Caribbean.

Keywords: Chronicle of an announced death, The colonel has no one to write with, right, literature

Resumo: 0 exame da união entre direito e literatura iniciou-se há relativamente pouco tempo, circunstância ainda é notável, considerando a pluralidade de exemplos que mostram que o vínculo entre as duas disciplinas é mais que centenário. Crônica de uma Morte Anunciada e Ninguém Escreve ao Coronel, narrativas de Gabriel García Márquez, constituem exemplos notáveis de como o direito é expressa na literatura, que por sua vez propõe uma nova leitura deste tipo de conteúdo e permite raciocinar de maneiras inovadoras 0 universo do que o homem do comum denomina, não sem certa reticência, o legal. 0 estudo dessas duas expressões da narrativa garciamarquiana, entendidas como interpretações jurídicas da realidade, constituem um campo fértil para especificar, por um lado a análise de lesões que causam os direitos em suspense no tecido social; e, por outro, a degradação da justiça quando está ausente em qualquer canto do Caribe latino-americano. 
Palavras-chave: Gabriel García Márquez, Crônica de uma morte anunciada, Ninguém Escreve ao Coronel, direito, literatura.

Résumé: L'étude des relations entre le droit et la littérature a débuté il ya relativement peu de temps, ce qui est remarquable compte tenu de la pluralité des exemples qui montrent que le lien entre les deux disciplines est plus que centenaire. Chronique d'une mort annoncée et Pas de lettre pour le colonel les récits de Gabriel García Márquez, sont des exemples remarquables de la manière dont le droit est exprimé dans la littérature, qui propose à son tour une nouvelle lecture de ce type de contenu et permet de raisonner de manière nouvelle l'univers de ce que l'homme ordinaire appelle, non sans une certaine réticence, le légal. L'étude de ces deux expressions du récit de García Marquez, compris comme interprétations juridiques de la réalité, constitue un champ fertile pour préciser, d'une part, l'analyse des dommages qui font naître des droits en suspens dans le tissu social; et de l'autre, la dégradation de la justice lorsqu'elle est absente dans n'importe quel coin des Caraïbes latino-américaines.

Mot-clés: Gabriel García Márquez, Chronique d’une mort annoncée, Pas de lettre pour le colonel Droit, littérature.

Decir que la literatura no nos ofrece "resultados" ni "métodos" como los de las ciencias sociales no significa que no nos ofrece nada, o que lo que nos ofrece puede ser relegado a un aspecto trivial de la vida, como si se tratara de una forma de entretenimiento o un adorno, como si lo que ofreciera fuera una cuestión de "estilo" más que de "sustancia" o de "sentimiento" más que de "pensamiento". Sería patético pensar que no tenemos nada que aprender de Sófocles o Shakespeare, por ejemplo, simplemente porque ellos no aportaron resultados o métodos que se puedan aplicar en el análisis de cuestiones jurídicas: equivaldría a eliminar todo lo que representa la alta cultura, tanto para nosotros como personas, como para nuestra profesión. Por otro lado, decir (como algunos podrían verse tentados a hacerlo) que tenemos "mucho que aprender de la literatura", 
pero "solo como personas, no como abogados", implicaría una mirada igualmente triste del derecho y de nosotros mismos, porque lo que la frase sugiere es que lo que hacemos con nuestros pensamientos y nuestros

sentimientos a lo largo del día es una mera técnica, que permanece indemne ante lo que pensamos, una técnica que no conmueve ningún aspecto significativo de nuestro ser. Desde esa perspectiva, ¿quién querría convertirse en abogado? James Boyd White, 2015

\section{Introducción}

¡Te demandaré! es una de las expresiones más fuertes que, cuidando las formas, la lengua nos regala. Si se discurre sobre ella es una sentencia realmente terrible. Anuncia la imposibilidad del acuerdo, el inicio de la batalla, el fin del diálogo razonado y razonable, la última instancia antes de que la violencia física haga presencia con sus devastadores resultados. Paradójicamente también es la voz de la esperanza, el testimonio de fe que los ciudadanos depositan en que ese "algo" que se denomina "justicia", aparecerá en medio del conflicto para orientar el desacuerdo hacia la armonía y el orden social.

En consecuencia, la ley existe porque existe la violencia, no de otra manera se explica su naturaleza. Afirma esta idea su afán por regular hasta el último de los rincones de la actividad humana, desde los más iluminados hasta los más oscuros. Cada vez que de la mano de parlamentos y gobernantes la ley encuentra el camino de su génesis, evidencia su abrumadora desconfianza en la capacidad de las pasiones humanas para moderarse, y su convicción de que para alcanzar concreción los procesos creativos requieren de alguna manera de la normalización que los protege e impulsa.

El derecho, que no es la ley, o mejor dicho que no es la regla restrictiva o permisiva pero que en todo caso es ordenador, es la capacidad de ejercer la posibilidad de ser y de hacer, de 
crear y disentir y avanzar hacia la materialización de la realización personal y colectiva, aunque sea menester reconocer que, aún hoy, barruntar una definición sobre lo que comporta esta palabra es una obra en construcción y en ello la literatura ha aportado lo suyo: "Novalis, el romántico alemán que se propone poetizar, es decir, redimir poéticamente al Todo, escribe en uno de sus fragmentos: "Yo soy un hombre totalmente ilegal; no poseo el sentido ni la necesidad del derecho"” (Magris, 2008, p. 23), sin embargo, expresarse creativamente, en este caso con algo de anarquía, es factible gracias a ese otro "algo" que es este sustantivo de tan difícil definición:

El hombre no es una cosa, y por tanto no es algo que puede ser usado como mero instrumento, sino que tiene que ser tenido en todas sus acciones siempre como fin en sí mismo. El imperativo práctico es, por tanto, el siguiente: actúa de tal manera que nunca utilices la humanidad como mero instrumento ni en tu persona ni en la persona de los demás (Kant, 2002, p.166).

La cuestión que plantea Immanuel Kant (1724-1804) al preguntarse ¿qué es el derecho? ha sido preocupación permanente de la literatura. Acudir al desván de la memoria parece útil para documentar esta afirmación. En ella será fácil encontrar ejemplos que permiten ilustrar este inveterado interés. Ya en el año 442 a.C. Antígona proponía reflexionar sobre el acto injusto, el derecho violado y el castigo que deviene del mismo:

Tiresias: En fin, tienes que saber, pero que muy bien, que ya no pasarás muchas revoluciones consecutivas del sol sin que dentro de este breve plazo de tiempo no hayas permutado tú mismo a uno, fruto de tus propias entrañas, ya cadáver, en compensación de otros cadáveres, por cuanto, por un lado, has arrojado abajo a una persona propiedad de los dioses de arriba y has enterrado su vida indignamente dentro de un sepulcro, y, por otro, mantienes aquí, por el contrario, un cadáver propiedad de los dioses de abajo, expoliado en sus derechos, exento de honras fúnebres, execrado. Dioses infernales sobre los que ni tú ni los dioses de arriba tenéis competencia y, sin embargo, sufren 
por ti este acto de fuerza. Reprobadoras de ello, te acechan dispuestas a destruirte en cualquier momento las Venganzas de Hades y de los dioses, para que seas apresado en las redes de estas mismas afrentas (Sófocles, 2014, p.24).

La obra de Sófocles no solo es ontológica en lo que al derecho se refiere, y por ello es de cierta manera fundante a la hora de estudiar la relación entre lo jurídico y lo literario, además, abarca otros problemas de tipo legal como, por ejemplo, si las potestades temporales se deben subordinar o no a los poderes celestiales, asunto que ha ocupado a los teóricos del derecho por espacio de algo más de diecisiete siglos. Es, a no dudarlo, una reflexión de la tensión entre culpa e inocencia, entre permisión y castigo.

Si se repara sobre lo expresado, evidente resulta que la literatura generosamente le abrió de tiempo atrás sus contenidos al derecho, para que este hiciera uso de ellos y encontrara dónde aposentarse con tranquilidad. Paradójicamente la teoría jurídica no se comportó de la misma manera. Solo hasta las últimas décadas del siglo XX inició la reflexión, aún en proceso de concreción, sobre cómo el derecho se expresa en la literatura y cómo a partir de esta es posible enriquecer el diálogo legal. El juez, basado en el clásico Da mibi factum, dabo tibi ius ${ }^{2}$, ejerce desde hace siglos el poder normalizador que reviste su autoridad con el propósito de hacer cumplir sus decisiones. Es claro que sus facultades provienen de los límites que el derecho le impone, para actuar de la forma en la que se espera que lo haga y en ello la creatividad y la flexibilidad parecen proscritas.

¿Cómo se nutre entonces el derecho de la narrativa si sus naturalezas, sus causas y sus fines son diferentes? Tan distantes resultan que el primero trata de racionalizar la conducta de los individuos para alcanzar la armonía social, mientras que la narrativa "es una búsqueda verbal de lo que espera ser escrito" (Fuentes, 1993, p. 36), reparando en solo una de las múltiples

2 Aforismo latino propio del derecho civil romano que traducido al español significa: “Dame los hechos y yo te daré el derecho". 
definiciones que a este concepto se pueden arrimar. A pesar de las diferencias no estamos ante conceptos antitéticos, por el contrario, se trata de disciplinas simbióticas que "sacan provecho de la vida en común" (RAE, 2011).

¿Por qué, entonces, oponer las humanidades a las ciencias, como si éstas fuesen menos humanas que aquéllas, y como si no fuesen precisamente las ciencias las que alcanzan el conocimiento más profundo y adecuado del hombre? Dígase más bien que las ciencias y las llamadas humanidades no son antagónicas sino complementarias, aun reconociendo que en la época contemporánea el centro de la cultura se desplaza de las humanidades a las ciencias (Bunge, 1960, p. 68).

A partir de la complementariedad pregonada por Bunge, válido es pensar que derecho y literatura son pares naturalmente hermanados por el lenguaje. En ese sentido Diego Valadés recuerda que "como fenómeno cultural, el derecho es tan estable o tan dinámico como el lenguaje a través del cual se expresa" (Narváez, 2017, p. 24). A la par, Carlos Fuentes destaca que "la novela ni muestra ni demuestra al mundo. Crea complementos verbales al mundo" (Fuentes, 1993, p. 22), en este caso, al mundo de lo legal.

Si consideramos la posibilidad de que a pesar del rigor propuesto por el derecho, dada su función en la sociedad puede ser complementado por una disciplina como la literatura, que es abrevadero permanente de novedad, incluso en el sentido literal del sustantivo, podremos decir que contamos con un instrumento realmente importante y por demás potente para darle una segunda lectura al ámbito en el que se desarrolla la juridicidad y, a partir de ello entenderlo y aplicarlo de maneras diferentes, y por lo que podríamos aventurar, insospechadas.

El papel de la narrativa en la construcción del entramado legal adquiere una especial relevancia, pues en sus decisiones el juez no solo escribe para las partes interesadas, en realidad lo hace para el conjunto de la sociedad. Las ficciones, en consideración a esa finalidad, se convierten en instrumento sustantivo de 
la argumentación jurídica dado que facilitan las posibilidades del operador judicial de explicar el porqué de sus sentencias. De la fortaleza de la argumentación jurídica se deriva la convicción social de que, encarnado en una decisión, el derecho es la expresión escrita de "la justicia" y, valga el énfasis, no aquella que se considera como ideal sino la que resulta ejercida en el plano estrictamente material. En consecuencia, el derecho "no puede estar exento de una corriente revitalizadora que lo resignifica como disciplina humana" (Narváez, 2017, p. 21) y ello se lo otorga generosamente la literatura.

Explicada la intersección entre derecho y literatura, se hace menester reparar en la narrativa, entendida de modo general como interpretación jurídica de la realidad. En ella la creatividad se mezcla y confunde con la ideología, con la posición política o con la mirada crítica que de la sociedad o de sus normas tiene quien la produce. Esa amalgama de posiciones y posibilidades es la que se refleja en mayor o menor medida en la composición escrita. Y a ese ello corresponde la influencia que impulsa la actividad del jurista cuando construye el discurso con el que desde la técnica legal persuade a la sociedad de que legítimamente encontrará en las decisiones judiciales la respuesta a su pedido de justicia.

La norma jurídica no es pura en el sentido kelseniano ${ }^{3}$ de la cuestión, su aplicación obedece a momentos sociales y políticos concretos, a coyunturas culturales, a conflictos o a consensos que determinan, a lo menos en parte, su necesaria adscripción a la sociedad. Más aún, en un mismo ordenamiento la misma norma puede ser operada de manera distinta por jueces que se

\footnotetext{
3 Se hace referencia a la Teoría Pura del Derecho, obra de Hans Kelsen en la que se sitúa la siguiente cuestión en palabras de García y De Fazio:

La pureza en la doctrina kelseniana se relaciona con la tesis de la independencia que, de un lado, significa la separación entre el ser y el deber ser, en virtud de la cual no es posible justificar enunciados normativos mediante enunciados empíricos y, de otro, exige que la justificación de los enunciados normativos se refiera únicamente a otros enunciados normativos. El derecho en la teoría pura es un orden normativo, porque lo concibe desde el deber ser objetivo que comportan las normas que lo integran. Una norma es lo que "debe ser", es decir, lo que se espera que oriente una determinada conducta (García \& De Fazio, 2015).
} 
formaron en los mismos años en las mismas aulas y a quienes solo separa la pared que distingue la sala de decisión. De la manera en la que cada juzgador interpreta el querer normativo del legislador es posible que se colijan las influencias que pesan en su formación como humanista, más que de aquellas que devienen de su vocación de jurista. Es en este punto en el que las distintas expresiones narrativas juegan un papel fundamental en la construcción del diálogo con la sociedad que nace desde lo judicial.

Mario Vargas Llosa sostiene en García Márquez: historia de un deicidio (1971) que "un escritor no elige sus temas, los temas lo eligen a él" (p. 95). De ser así, al escritor colombiano lo escogió la violencia y las diversas formas en las que la justicia se expresa en su Caribe natal: aquella que se ejerce por mano propia y otra más que cabalga sin llegar y que deja frustrados a sus eternos esperadores. En términos del Nobel peruano, en un acto de rebeldía García Márquez toma la decisión deliberada de 'asesinar la realidad', y al hacerlo crea un universo en el que lo mágico se acerca a lo jurídico y se vincula de una manera tal que termina por confundirse en sus relatos, las más de las veces, como el testimonio de que la ficción suele ser superada por la veracidad.

Crónica de una muerte anunciada y El coronel no tiene quien le escriba, narrativas breves de Gabriel García Márquez, constituyen ejemplos notables de la manera como el derecho se expresa en la literatura, la que a su vez propone la relectura de este tipo de contenido, al permitir entender de maneras novedosas el universo de lo que el hombre del común denomina, no sin cierta reticencia, lo legal.

El estudio de estas dos expresiones de la narrativa garciamarquiana, entendidas como interpretaciones jurídicas de la realidad, se constituye en consecuencia en un campo fértil para concretar, de una parte, el examen de las lesiones que causan en el tejido social los derechos en suspenso, perdidos en el laberinto indescifrable de trámites burocráticos, que a la par se convierten en el último campo de batalla del coronel sin nombre 
que libra una guerra sin cuartel contra el hambre y la desesperación en un pueblo perdido. Y, de la otra, la degradación de la justicia cuando esta brilla por su ausencia en cualquier esquina del Caribe latinoamericano.

\section{Objetivo general}

Establecer la relación que existe entre la narrativa garciamarquiana en El coronel no tiene quien le escriba y Crónica de una muerte anunciada y la manera en que desde el punto de vista jurídico dichas obras interpretan la realidad. A partir de la identificación de dicha relación será posible establecer la influencia de estas novelas en el proceso de construcción del entramado constitucional que las sucedió cronológicamente.

\section{Objetivos específicos}

1. Identificar los elementos típicamente legales de carácter constitucional presentes en la narrativa garciamarquiana objeto de análisis.

2. Analizar el discurso jurídico propuesto por García Márquez en Crónica de una muerte anunciada y El coronel no tiene quien le escriba mediante una lectura cruzada con la regulación constitucional aplicable al momento en que dichas novelas fueron escritas, a efectos de precisar la influencia del estado de cosas normativo en el proceso de concreción de dichas obras.

3. Establecer la influencia de las obras de García Márquez en la construcción de la argumentación jurídica posterior a la publicación de Crónica de una muerte anunciada y El coronel no tiene quien le escriba.

\section{Metodología}

Para el desarrollo de este documento se realizó una lectura cruzada de Crónica de una muerte anunciada y El coronel no 
tiene quien le escriba, para identificar en dichas narrativas los problemas de tipo constitucional propuestos por el autor.

A partir de dicha identificación se estableció el correlato entre el contexto jurídico constitucional colombiano en el que fueron escritas las obras y el que sobrevino con posterioridad a la promulgación de la Constitución de 1991 (hoy vigente), en el propósito de establecer el impacto de dichas obras en la argumentación jurídica de carácter fundamental que las sucedió.

A este efecto se acudió a la lectura del texto fundamental y a la revisión de las sentencias de la Corte Constitucional en el periodo 1991 y 2017, con el propósito de establecer si las obras objeto de estudio fueron o no tenidas en cuenta por dicho órgano como parte del recurso argumental para la construcción de sus providencias, en la intención de establecer el impacto que la narrativa garciamarquiana ha tenido en el desarrollo del discurso jurisdiccional en Colombia.

\section{La relación entre el derecho y la literatura: estado de la cuestión}

El derecho de tradición latina se expresa esencialmente por escrito. Es una forma de narrativa que acude a distintos recursos para decir aquello que sirva al propósito perseguido en cada situación.

¿Qué es una demanda sino una narrativa, que sustentada en argumentos de tipo legal permitirá al lector-juez decidir quién tiene el derecho en una determinada cuestión?

¿Qué es la ley, literariamente hablando, sino la expresión de un supuesto de hecho que en ciertas circunstancias comporta una consecuencia previamente determinada para su cumplimiento o inobservancia?

En consecuencia, la juridicidad es una forma del lenguaje, no solo desde el punto de vista técnico también desde lo discursivo-argumental. En este último aspecto la construcción de su narrativa conserva mayores flexibilidades, sin que ello proscriba 
la posibilidad de reconocer que aun en lo estrictamente técnico el derecho se reserva licencias con cierta dosis de elementos narratológicos e incluso poéticos, tal y como se aprecia en los códigos civiles europeos y latinoamericanos de los siglos XVIII y XIX.

A efectos de demostrar esta afirmación, valga la pena apreciar el relato que es posible construir a partir de un aparte del Código Civil colombiano Las vicisitudes del animal bravío.

Código Civil colombiano. Artículo 687. Animales bravíos, domésticos y domesticados. Se llaman animales bravíos o salvajes los que viven naturalmente libres e independientes del hombre, como las fieras y los peces; domésticos, los que pertenecen a especies que viven ordinariamente bajo la dependencia del hombre, como las gallinas, las ovejas, y domesticados los que, sin embargo de ser bravíos por su naturaleza, se han acostumbrado a la domesticidad, y reconocen en cierto modo el imperio del hombre.

Estos últimos, mientras conservan la costumbre de volver al amparo o dependencia del hombre, siguen la regla de los animales domésticos, y perdiendo esta costumbre vuelven a la clase de los animales bravíos.

Código Civil colombiano. Artículo 693. Ocupación de animal bravío. Se entiende que el cazador o pescador se apodera del animal bravío y lo hace suyo desde el momento que lo ha herido gravemente, de manera que ya no le sea fácil escapar, y mientras persiste en perseguirlo, o desde el momento que el animal ha caído en sus trampas o redes, con tal que las haya armado o tendido en paraje donde le sea lícito cazar o pescar.

Si el animal herido entra en tierras ajenas donde no es lícito cazar sin permiso del dueño, podrá este hacerlo suyo. Código Civil colombiano. Artículo 694. Persecución de animal bravío por otro cazador o pescador. No es lícito a un cazador o pescador perseguir al animal bravío, que ya es perseguido por otro cazador o pescador; si lo hiciere sin su consentimiento, y se apoderare del animal, podrá el otro reclamarlo como suyo. 
El reconocimiento del valor literario inmerso en el texto legal no es menor, ni ha pasado desapercibido a lo largo de la historia de la literatura. Sthendal (1783-1842) en carta enviada a Balzac (1799-1850) en 1840 al comentar sus avances en la redacción de su novela $L a$ Chartreuse le decía: "para tomar el tono, cada mañana, yo leía dos o tres páginas del Código Civil, a fin de ser siempre natural" (Narváez, 2017, pp. 22-23).

Sin embargo, por ahora no resulta de nuestro interés estudiar el derecho como literatura, campo que de por sí abre enormes posibilidades, sino dedicarnos a la investigación del derecho en la literatura en la medida en que permite explorar nuevas maneras de acercarse al universo jurídico y facilitar el diálogo de este con los colectivos sociales cuyas relaciones pretende regular.

Así las cosas, sea menester señalar que a partir de la década del ochenta el Movimiento de Derecho y Literatura se instaló en el ámbito académico, principalmente en las universidades de habla inglesa, como una corriente de la teoría crítica del derecho en la que se promueve de manera general la idea de que es necesario hacer una lectura de la narrativa jurídica en sus distintos niveles, orientada a trascender el dogmatismo impuesto por el positivismo o por la interpretación analítica de los textos legales (Roggero, 2015, p. 11).

Sin embargo, en Hispanoamérica la reflexión se encuentra en proceso de concreción. Los textos orientados a estudiar el impacto de la literatura en el mundo del derecho son escasos, aunque curiosamente la narrativa está presente en las facultades de derecho desde su génesis. A manera de ejemplo, valga recordar que desde su publicación El proceso, para solo hacer referencia a lo que concierne al siglo XX, ha sido una obra de lectura obligada para quienes se forman como juristas, no por la condición de doctor en leyes de Franz Kafka, su autor, quien de hecho nunca fue un teórico de la ciencia jurídica en el sentido formal de la expresión, sino por la forma en la que narra la desesperación de quien se encuentra indefenso ante el poder abrumador del aparato judicial. 
Cada vez que un juez advierte la necesidad de ilustrar la vulnerabilidad del individuo respecto a la silente pesadez del aparato estatal, acude a Kafka en términos como los que a continuación se presentan:

Es conveniente advertir también que el sentido y alcance de la ley debe asumirlo el intérprete y el ejecutor buscando su genuino cumplimiento, antes que prefabricando mecanismos de elusión o entrabamiento, pues además no estaría bien continuar contemporizando con ese proceder inserto en la historia que narra Kafka sobre el hombre que llega ante el guardián de la ley con el fin de ser admitido, pero que por culminante respuesta sólo recibe una puerta que se cierra (Consejo de Estado, 1998, p. 7).

Sin duda el apartado en cita es a todas luces pertinente, sin embargo, el reconocimiento que hace no impide reparar en que la tendencia natural del juez hispanoamericano es la de acudir a narrativas lejanas en tiempo y lugar, lo que si bien no le resta valor a su discurso desde la perspectiva de la lógica argumental, sí genera a lo menos duda acerca de ¿por qué acudir a Kafka y no a García Márquez, a Vargas Llosa, a Cortázar o a Borges para ilustrar la misma cuestión? ¿Acaso el coronel, que cada viernes espera la carta que nunca llega, en la que por fin se reconocerá el derecho que reclama, no es más cercano en sus fatigas al ciudadano de a pie de cualquiera de las geografías de herencia latina que las que padeció Josef K? ¿No es para él la misma culminante respuesta de la puerta que se cierra?

La respuesta es sí, indiscutiblemente sí. Sin embargo, la argumentación jurídica en estas latitudes aún no se edifica a partir de su propia narrativa, en la que la emocionalidad juega un papel determinante.

Adam Smith (1723-1790) sostiene que no resulta defensable la idea de que la racionalidad, estrictamente considerada, fuera ajena a la emocionalidad. En La teoría de los sentimientos morales indica: 
Las emociones apropiadas, es decir, las que son puramente racionales, son útiles para mostrarnos lo que podríamos hacer, y además poseen su propio valor moral, como reconocimiento del carácter de la situación que enfrentamos. Más todavía, motivan una acción adecuada... Si no partimos de la "Fantasía" para interesarnos en esas figuras humanas, sintiendo compasión por sus sufrimientos y alegría ante su bienestar; si no valoramos la importancia de encarar a cada persona como un individuo de una vida singular, nuestra crítica de las emociones perniciosas carecerá de fundamento (Mari, 2015, p. 218).

En armonía con el argumento de Smith, es menester reparar en el ámbito de la construcción del diálogo legal. Al apelar al reconocimiento de la emocionalidad como un factor inherente al individuo, destinatario de la decisión judicial o de la regla de derecho, lo que se propone es la concreción de un discurso fundamentado en la narrativa literaria como instrumento adecuado para conectar el dictado de la norma con los padecimientos de quien espera se aplique justicia en su caso. La narrativa se ofrecerá entonces, en términos de Carlos Fuentes, "como posibilidad pero también como inminencia: la novela como creadora de la realidad". En armonía con ello "una nueva realidad, invisible antes de ser escrita" (Fuentes, 1993, p. 24). Una realidad que armonizada con el texto legal sensibiliza a la sociedad sobre los efectos del problema que el juez resuelve.

A pesar de su dimensión universal, los textos de Gabriel García Márquez se reflejan poco, poquísimo, en la jurisprudencia colombiana, primera fuente después de la Constitución y la ley del lenguaje de lo legal. De hecho, solo cinco casos utilizan estas narrativas para ilustrar esta cuestión, tal como se mostrará más adelante.

No deja de sorprender que en las decisiones de la Corte Suprema de Justicia el Consejo de Estado y la Corte Constitucional colombianas prima facie: Sófocles, Miguel de Cervantes, Charles Dickens, Franz Kafka, George Orwell, Ernest 
Hemingway y Albert Camus sean más citados que el autor que estudiamos $^{4}$, lo que al precipitar hipótesis nos llevaría a pensar, en principio, que el influjo del nacionalismo literario no es un factor determinante a la hora de establecer el ascendiente de un determinado escritor respecto de los operadores jurídicos de su propia jurisdicción, para utilizar un lenguaje legal correcto.

Una segunda posibilidad en la que vale la pena reparar es la inexistencia de trabajos que, salvo la mención a citas aisladas del trabajo de García Márquez, permitan colegir que el autor no obstante su dimensión universal, ha influido en el proceso de construcción del pensamiento jurídico constitucional de la manera en la que lo pudieron hacer Kafka con El proceso, Sófocles con Edipo rey o más recientemente, George Orwell con Rebelión en la granja, solo para manir sobre lo ya dicho.

Queda entonces aproximarse al autor que nos ocupa a partir de la forma en la que entendió el derecho y lo expresó en su obra, que es el objeto central de este escrito. En esa dirección, el derecho penal ha dado pasos más que relevantes. Al respecto cabría recordar el trabajo de Antonio Cancino en el que hace un recorrido por el derecho penal colombiano a partir de la lectura extensa del trabajo garciamarquiano.

Gabriel García Márquez es un penalista sin formalismos, va tan de prisa, tan urgido de justicia, que no puede detenerse a esperar un pergamino que lo acredite. Además no existe aún el registro en el que se pueda inscribir un abogado de causas universales, que no se pueden reducir a los convencionales límites del proceso. Ha tenido que acudir a nutrirse con la jurisprudencia constante que la humanidad produce desde el burdel de Pilar Ternera hasta los palacios de los Presidentes que en el mundo han sido, para poder empaparse de la angustia de los hombres. Ha litigado sin sujeción a términos, ni distancias, con alegatos cuyo contenido se queda entrelazado en

\footnotetext{
4 Sobre este particular, resulta relevante el trabajo de Juan Francisco Soto Hoyos, Jurisprudencia literaria en Colombia: Ios usos de la literatura en las decisiones judiciales, publicado en la revista Summa luris, 2014, pp. 217-251.
} 
el tiempo y en el espacio, pues no existen tribunales creados con competencia suficiente para dictar fallos que contengan determinaciones universales con equilibrio general y persistente (Cancino Moreno, Cancino González \& Teleki, 2015, p.15).

El derecho constitucional, por su parte, a pesar de ser piedra angular del ordenamiento jurídico y que dada su condición positiva de derecho de los derechos debería ser más próximo a la influencia de la narrativa garciamarquiana, no cuenta con estudios relevantes sobre la temática expuesta. La afirmación no es menor si se repara en que García Márquez denuncia sin miramientos todo aquello que desde el punto de vista legal está mal en el país que le correspondió en suerte nacer o que lo vio partir. Reivindica sin timidez alguna los derechos que aparecen violados sistemáticamente en el universo literario que construye en sus ficciones, como se evidencia en Cien años de soledad, en el que hace un correlato de la realidad:

La ley marcial continuaba, en previsión de que fuera necesario aplicar medidas de emergencia para la calamidad pública del aguacero interminable, pero la tropa estaba acuartelada. Durante el día los militares andaban por los torrentes de las calles, con los pantalones enrollados a media pierna, jugando a los naufragios con los niños. En la noche, después del toque de queda, derribaban puertas a culatazos, sacaban a los sospechosos de sus camas y se los llevaban a un viaje sin regreso. Era todavía la búsqueda y el exterminio de los malhechores, asesinos, incendiarios y revoltosos del Decreto Número Cuatro, pero los militares lo negaban a los propios parientes de sus víctimas, que desbordaban la oficina de los comandantes en busca de noticias. "Seguro que fue un sueño -insistían los oficiales- En Macondo no ha pasado nada, ni está pasando ni pasará nunca. Este es un pueblo feliz.» Así consumaron el exterminio de los jefes sindicales (García Márquez, 2007, p. 351-352).

García Márquez hace evidente que el derecho existe porque existe la barbarie, de lo contrario sería innecesario, 
instrumentalmente hablando. No obstante, evidencia que durante centurias lo legal fue utilizado para subordinar, desconocer y, evidentemente, violentar las garantías de los asociados. Todo ello sin que el aparato judicial se nutriera de esta voz que desde la orilla de su narrativa daba cuenta de lo que a diario acontecía, bien como testigo, bien como denunciante.

\section{El autor y su obra}

Dice el diccionario: "Boom. Voz ingl. 1. m. Éxito o auge repentino de algo, especialmente de un libro. El boom de la novela hispanoamericana" (RAE, 2011). Si se mira bien, no deja de ser notable que una expresión inglesa se utilice para describir uno de los procesos de concreción más relevantes de la literatura en lengua castellana del siglo XX y que ello a su vez sirva para dar a dicha expresión carta de naturalización en este idioma.

El boom, que en lengua inglesa se define como " a loud, deep, resonant sound" (Oxford Dictionaries, 2018), es decir, un sonido fuerte, profundo y resonante, en realidad no pudo ser mejor definido por la lengua española ${ }^{5}$. Como movimiento literario no obedeció a una intención premeditada para establecer una manera de escribir o de interpretar la realidad

5 Explosión, que es la expresión más similar se define en los siguientes términos: “Del lat. explosio, - nis rabucheos, (acción de echar a una persona o un animal con ruidos.

1. f. Liberación brusca de energía que produce un incremento rápido de la presión, con desprendimiento de calor, luz y gases, y va acompañada deestruendo y rotura violenta del cuerpo que la contiene.

2. f. Dilatación del gas contenido en un dispositivo mecánico con el fin de producirel movimiento de una de las partes de este, como en el motor del automóvil o enel disparo del arma de fuego.

3. f. Manifestación súbita de ciertas emociones. Explosión de risa, de entusiasmo.

4. f. Desarrollo vertiginoso de algo. Explosión demográfica.

5. f. Fon. Ruido producido por la separación brusca de los órganos articulatorios durante la pronunciación de las consonantes oclusivas.

6. f. Mec. En los motores de combustión interna de cuatro tiempos, tercera fase del ciclo, en la que, al quemarse el combustible con el aire, se producen gases que en su expansión empujan el pistón" (RAE, 2011). 
latinoamericana, más bien se desarrolló como una forma de narrativa que "apostó fuertemente por el discurso de índole fantástica entendiéndose éste como metáfora de la existencia humana" (Alemany, 2009).

En efecto, al ser contada América Latina se convirtió en el telón de fondo para que sus escritores expusieran ante el mundo las facetas tragicómicas de sus dictaduras, las bananeras y brutales, entre otros hechos relevantes, sin que ello los ubicara, a lo menos mayoritariamente, en la esquina del activismo político y sin que proscribiera la posibilidad de hacer lecturas de sus narrativas con ese tipo de alcance.

La pobreza rayana en lo misérrimo en diálogo constante con la riqueza que parece salida de los mitos sobre tesoros coloniales; la cotidianidad de la provincia con sus casitas de colores y tejas de barro que rodean las plazas coronadas por iglesias y alcaldías, en la que los amores míticos, implacables e imposibles, como suelen ser los de estas tierras, coinciden en las páginas de esta pléyade de escritores sin que medie una proposición previa.

Los temas convergen generacionalmente sin que hayan requerido de invitación o de concertación, por eso el boom es un sonido profundo y resonante de una identidad en construcción. En términos de Mario Vargas Llosa:

Lo que se llama boom y que, nadie sabe exactamente que es, yo particularmente no lo sé, es un conjunto de escritores, tampoco se sabe exactamente quiénes, pues cada uno tiene su propia lista, que adquirieron de manera más o menos simultánea en el tiempo, cierta difusión, cierto reconocimiento por parte del público y de la crítica. Esto puede llamarse, tal vez, un accidente histórico (Rama, 2005, p. 167).

Y en medio de este accidente de la historia: Gabriel García Márquez. Sus textos repletos de imágenes toman elementos de las vivencias de su Caribe natal que acompaña con rasgos e influencias locales y universales, dando un resultado difícil de igualar. Captura la realidad. La funde con elementos mágicos, que no 
es otra cosa que la manera en que la literatura latinoamericana, por su conducto, se vale de lo real maravilloso, en términos de Alejo Carpentier (1904-1980), para narrar su cotidianidad en la que el ámbito de la implicancia de lo jurídico estará siempre al orden del día, lo cual no deja de ser relevante si se repara en que respecto de su formación jurídica este autor se definió de la siguiente manera: "Disimulé la ofuscación con un recuento espectral de mis estudios: bachillerato completo y bien calificado en un internado oficial, dos años y unos meses de derecho caótico, periodismo empírico" (García Márquez, 2002, p. 37).

Esos escasos años de derecho caótico le bastaron para convertirse en fuente para la reflexión legal, como se aprecia en su obra en lo que resulta sencillo ilustrar el punto que se propone.

Cien años de soledad, publicada en 1967, en la que se exploran problemas como las consecuencias jurídicas del incesto (cuestión aún sin resolver desde el punto de vista penal en varios ordenamientos legales); la violación de derechos humanos; el ejercicio de las garantías fundamentales en estados de excepción; el goce de los derecho de asociación y protesta; el derecho a la verdad en la justicia; el indulto; las garantías fundamentales a la educación y a la libertad de cultos, para mencionar una brevísima parte de las cuestiones de implicancia constitucional que a lo largo de una centuria pueden suceder alrededor de una familia que hace el mejor esfuerzo para que un hijo no les salga con cola de cerdo y fracasa en el intento.

El otoño del patriarca, escrito en 1975, en la que se aborda, desde la perspectiva de la teoría general del Estado, la fenomenología del poder y los instrumentos legales e ilegales que este tiene para mantenerse y perpetuarse, en los que no dejan de mezclarse cuestiones como la propiedad de los bienes de la nación, la violación de los derechos humanos, la importancia del control político al ejercicio del poder, así como todos aquellos que se desprenden de los efectos, predecibles por cierto, de una inveterada dictadura tropical.

La increíble y triste historia de la cándida Eréndira y de su abuela desalmada, escrita en 1972 y publicada en 1978, en la 
que García Márquez abre la discusión sobre los derechos de los niños, la esclavitud sexual, la trata de personas y la manera en la que dichas prácticas eran socialmente conocidas y aceptadas en el contexto sociotemporal en el que vivió el autor durante su niñez y juventud. A la par que propone un debate, plenamente vigente, por cierto, que de hecho se extenderá a por ejemplo Crónica de una muerte anunciada, sobre la equidad de género y el derecho de la mujer a decidir sobre la manera en la que se desarrolla su sexualidad.

El general en su laberinto, a manera de biografía novelada, publicada en 1989, Simón Bolívar (1783-1830) explora las causas que llevaron al fracaso de la Constitución de 1821 y, en consecuencia, desde la lógica de la Teoría General del Estado a la ruptura de la Gran Colombia ${ }^{6}$.

De esta manera sería posible valerse de las otras narrativas del novelista colombiano y, con base en sus contenidos, seguir enunciando la manera en la que su obra, constituye evidentemente una interpretación jurídica de la realidad.

\subsection{El coronel no tiene quien le escriba}

Taurinamente hablando El coronel no tiene quien le escriba abrió plaza en 1961. Publicada seis años después de La hojarasca (1955), se constituye en la segunda novela publicada por el Nobel colombiano. En ella se aprecian en toda forma los recursos de estilo que hacen inconfundible la narrativa garciamarquiana. El manejo de las expresiones y del símil para mezclar sabores con circunstancias, o sentimientos con olores, terminan por dar como resultado, lo que es notable por su brevedad, una obra de carácter universal.

No es un texto con una poética elaborada como la que se aprecia, por ejemplo, en El amor en los tiempos del cólera (2014), en la que hay un otro García Márquez que juega más

6 La Gran Colombia, creada legalmente en 1819, comprendía los territorios de Venezuela, Nueva Granada (hoy Colombia), Panamá y Ecuador y, geográficamente, parte de los territorios actuales de Perú, Bolivia, Brasil, Honduras y Nicaragua. 
con la narrativa y con las palabras y que en realidad pareciera estar más ocupado por elaborar un poema que por construir una novela "Fue entonces cuando Fermina Daza tuvo la revelación de los motivos inconscientes que le impidieron amarlo. Dijo: "Es como si no fuera una persona sino una sombra». Así era: La sombra de alguien a quien nadie conoció nunca" (García Márquez, 2014a, p. 290).

En El coronel no tiene quien le escriba el lenguaje es preciso, la historia no tiene giros temporales, la economía en los adjetivos es notable, como si se tratara de un guion cinematográfico el relato persigue a los personajes obligando al lector a situar su atención en los detalles que se obsequian respecto de cada uno de ellos "El lenguaje utilizado en El coronel no tiene quien le escriba, en La mala hora y en varios de los cuentos de Los funerales de la Mamá Grande es conciso, sobrio, dominado por una preocupación de eficacia tomada del periodismo" (Mendoza, 1982, p. 63).

Mantiene a lo largo de la obra dos tipos de evocación, una nostálgica respecto de tres elementos: (a) el hijo muerto, (b) las guerras libradas, y (c) los tiempos en que la vida del coronel se tramitaba con dignidad; y una evocación futura, principalmente asociada a la suerte que el gallo heredado correrá en la gallera, en el contexto de unas fiestas que, al igual que la carta siempre esperada, tampoco acaban por llegar.

La historia del coronel se circunscribe a su cotidianidad, en la que se mezclan diversos elementos de carácter político y jurídico: los mensajes cifrados que evidencian la imposibilidad de ejercer los derechos de asociación y de expresión; el toque de queda, instrumento por excelencia para restringir la capacidad jurídica de movilización y reunión; la memoria de la guerra civil, circunstancia en la que el orden jurídico queda en suspenso sino es que se extingue; el derecho a la pensión que no se concreta, que habla por sí mismo de la imposibilidad de ejercer el derecho a una vida digna; el laberinto administrativo en el que parece perdido para siempre el trámite pensional, lo que en sí mismo se constituye en una omisión al deber de 
conducta predicable del Estado y en una forma de violencia del mismo respecto de sus asociados; para no profundizar en la mención constante a la violencia, esa sí armada, de los partidos, el asesinato de Agustín a manos de la policía, todo ello en un tránsito interminable entre la casa que se cae a pedazos, el puerto, la oficina del telégrafo, la sastrería, y la casa del compadre del coronel fastidiosamente rico en medio de la miseria que lo rodea.

De otra parte, el pueblo innominado, en el que las penalidades parecen no dar tregua, y sirven de telón de fondo para una reflexión que se centra en dos aspectos sustanciales: el tiempo, que en este caso no puede ser entendido en el contexto de la cuarta definición del diccionario: "Época durante la cual vive alguien o sucede algo" (RAE, 2011), en la medida en que en la historia del coronel no ocurre nada, y en la que la vida de los protagonistas de la narrativa pareciera no tener propósito distinto que el de sobrevivir; y la violencia, que parece expresarse de distintas maneras y dejar en claro que al estar pegada a la piel de todos los personajes de este relato mantendrá su hegemonía y arbitrará la existencia de quienes se encuentran encarcelados en esa abrumadora realidad. “-Este entierro es un acontecimiento -dijo el coronel-. Es el primer muerto de muerte natural que tenemos en muchos años" (García Márquez, 2016, p. 12).

Especialmente interesante resulta como recurso narratológico, que la historia del coronel no tenga fin. No se sabe si la carta en la que se le reconoce su alegato pensional finalmente llega. Tampoco se establece si su mujer sobrevivirá a los ataques de asma que la afligen o si el hambre y la desesperación, que no ofrecen descanso, acabarán con su familia. También se ignora si el gallo heredado sobrevivirá hasta llegar a la anhelada riña o si de ella saldrá victorioso cambiando para siempre la realidad de los protagonistas.

En consecuencia, la trama del coronel es la expresión de una narrativa inacabada en la que lector y personajes terminan inmersos en una realidad que carece de solución y de límites de 
temporalidad, por lo cual las respuestas posibles a la concreción de la historia propuesta son tantas como lectores puede haber.

\subsubsection{Contexto histórico}

La paz es una noción extraña en el contexto colombiano. Incluso, la más austera de las definiciones, que es la que propone el diccionario y se presenta como la "situación y relación mutua de quienes no están en guerra" (RAE, 2011), no ha sido predicable en ningún momento de la convulsionada historia local.

Antes de concluir la guerra de Independencia en 1819, Colombia ya había padecido al menos una guerra civil. Ello, sin hablar de conflictos coloniales anteriores que terminaron en levantamientos armados relevantes, asociados a los impuestos al cultivo y a la comercialización de algunos productos agrícolas y que son reseñados en los textos de historia de Colombia como los de la revolución de "Los Comuneros"7.

A lo largo del siglo XIX la vida republicana colombiana se vio signada por nueve guerras civiles de orden nacional y decenas de alzamientos de carácter regional que cobraron un número de víctimas aún sin precisar (Pardo Rueda, 2004, p. 43).

Sin excepción, todos los conflictos nacionales concluyeron con acuerdos que condujeron a procesos constituyentes que en ningún caso fueron la expresión de consensos entre vencedores y vencidos, sino más bien manifestaciones regladas, vertidas en forma de normas de tipo constitucional, de los pactos a los que fueron llegando los ganadores.

En consecuencia, las constituciones de 1821, 1830, 1832, $1843,1853,1858,1863$ y 1886, todas las del siglo XIX, fueron la conclusión unísona de conflictos militares que, una vez agotados en sus motivaciones, solo podían ser el preámbulo de sucesivas confrontaciones armadas y, por supuesto, de una constelación

7 Sugiero consultar a Indalecio Liévano Aguirre (2002). Los grandes conflictos sociales y económicos de nuestra historia. 
de posteriores cartas fundamentales ${ }^{8}$ iA mali tempore plurima legem!?.

Si bien la Constitución de 1886, que regiría hasta 1991, no se vio modificada como consecuencia de un gran conflicto de carácter nacional, si fue llamada a desaparecer debido a la fatiga de material ${ }^{10}$ que en su estructura ocasionó un siglo de diversas violencias y cuestiones políticas, que por sus efectos en la sociedad la convirtieron en un instrumento inviable para asegurar la vida comunitaria en condiciones de civilidad.

Al ser la búsqueda de la paz una obsesión histórica desde el punto de vista constitucional, no es de sorprender que la violencia, punto de partida y final de todos los procesos constituyentes colombianos, se exprese en la obra de García Márquez como un tema medular en el que, por supuesto, la narrativa de El coronel no tiene quien le escriba no puede ser la excepción.

La historia del coronel fue escrita en el contexto de la vigencia de la Constitución de 1886, carta política de estirpe conservadora que rigió en el país por algo más de cien años. En virtud de esta disposición, por vía de decretos, normas ejecutivas del presidente de la República, era posible para el gobierno suspender o limitar derechos que a su discreción se entendieran como elementos de ralentización del control del orden público en el territorio nacional.

Al estado de cosas constitucional se agregó la dictadura militar, protagonizada por el general Gustavo Rojas Pinilla (1900-1975), la cual se extendió del 13 de junio de 1953 al 10 de mayo de 1957, periodo durante el cual se cerraron varios medios de comunicación, entre otros El Espectador, el diario

8 Sugiero consultar a Carlos Restrepo Piedrahíta (1995) Constituciones Políticas Nacionales de Colombia. Segunda Edición. Bogotá. Colombia. Instituto de Estudios Constitucionales Carlos Restrepo Piedrahita, Universidad Externado de Colombia.

9 Aforismo latino que en lengua castellana se traduce como ¡A mal tiempo más leyes!

10 Tomamos prestada esta definición de la ingeniería entendiendo que la fatiga de material es la "pérdida de la resistencia mecánica de un material, al ser sometido largamente a esfuerzos repetidos" (RAE, 2011). 
más antiguo del país y casa editorial desde la cual García Márquez ejercía su actividad periodística.

Plinio Mendoza relata este capítulo de la trama vital de García Márquez, para ese momento exiliado en Francia, de la siguiente manera:

Escribió El coronel no tiene quien le escriba en parte para despejarle el camino a La mala hora y en parte también para exorcizar literariamente sus angustias cotidianas de entonces: también él, como su personaje, no sabía cómo iba a comer al día siguiente y aguardaba siempre una carta, una carta con dinero que nunca llegaba. Sus problemas económicos habían empezado con una noticia de tres líneas aparecida en Le Monde, que leímos al tiempo en un café de la rue des Ecoles: Rojas Pinilla, el dictador que entonces gobernaba a Colombia, había clausurado $E$ I Espectador, el diario del cual Gabriel era corresponsal en París. "No es grave", dijo éste. Pero sí lo era. Las cartas nunca volvieron a traer cheques y un mes después no tenía cómo pagar el hotel (Mendoza, 1982, p. 69).

Al igual que el protagonista de su narrativa, García Márquez termina deambulando por las calles de París, trabando un combate diario contra la pobreza y el hambre en espera de una carta que nunca terminará por llegar. Experiencia vital que sin duda contribuirá a la caracterización de sus personajes.

\subsubsection{Problemas constitucionales asociados a la obra y aproximación jurisdiccional}

El coronel lleva quince años esperando la carta en la que se reconocerá su derecho a la pensión. Lo hace en el contexto de un pueblo olvidado sometido por la fuerza de la violencia a la censura impuesta por el Estado y la iglesia.

Un poco después de las siete sonaron en la torre las campanadas de la censura cinematográfica. El padre Ángel utilizaba ese medio para divulgar la calificación moral de la película de acuerdo con la lista clasificada que recibía todos los meses por correo. La esposa del coronel contó 
doce campanadas. -Mala para todos -dijo-. Hace como un año que las películas son malas para todos (García Márquez, 2016, p. 22).

Corría el año 1956. Para ese entonces la Constitución de 1886 no prohibía la censura a pesar de que en el contexto de las sociedades de occidente la libertad de expresión era de lejos, y por mucho, un valor unánimemente reconocido como parte de aquellos que resultan fundantes para la vida democrática.

De otra parte, al referirse al derecho pensional la Constitución vigente, silente en temas medulares en la materia, sostenía:

Artículo 62. - La ley determinará los casos particulares de incompatibilidad de funciones; los de responsabilidad de los funcionarios y modo de hacerla efectiva; las calidades y antecedentes necesarios para el desempeño de ciertos empleos, en los casos no previstos por la Constitución; las condiciones de ascenso y de jubilación; y la serie o clase de servicios civiles o militares que dan derecho a pensión del Tesoro público (Constitución Política de Colombia, 1886).

Y más adelante la misma norma fundamental agregaba:

Artículo 169. - Los militares no pueden ser privados de sus grados, honores y pensiones, sino en los casos y del modo que determine la ley (Constitución Política de Colombia, 1886).

De una sana lectura de las normas, desde el punto de vista constitucional resulta en consecuencia que el coronel, así no hubiese quien se lo reconociera, tenía en efecto derecho a la pensión reclamada, en lo que no deja de destacarse que, a pesar de tener una formación caótica en materia jurídica, tal y como ya se anotó, en su narrativa García Márquez se esmeró por cuidar las formas propias de lo legal. Rasgo destacable, en términos de realismo literario y relevante a la hora de estudiar las intersecciones que existen entre derecho y literatura.

Durante la lectura pensó en su pensión de veterano. Diecinueve años antes, cuando el congreso promulgó la ley, 
se inició un proceso de justificación que duró ocho años. Luego necesitó seis años más para hacerse incluir en el escalafón. Esa fue la última carta que recibió el coronel (García Márquez, 2016, p. 35).

Capítulo aparte merece el derecho a la salud. Nada de nada decía la Carta Política de 1886 sobre este tema y en ello hay un correlato en la narrativa garciamarquiana en el que se difiere el ejercicio de esta garantía fundamental a la práctica privada del médico del pueblo, que en su talante bonachón financiaba eternamente a sus pacientes.

-Cuánto le debemos, doctor.

-Por ahora nada -dijo el médico, y le dio una palmadita en la espalda-. Ya le pasaré una cuenta gorda cuando gane el gallo (García Márquez, 2016, p.27).

En este punto García Márquez parece situarse en la esquina del activismo literario al denunciar que en el contexto de la Colombia de ese entonces, solo aquellos, que contaban con recursos para lograr la atención médica que necesitaban podían gozar de manera más o menos razonable del derecho a la salud, defecto que se vino a corregir solo hasta la entrada en vigencia de la Constitución de 1991, en la que se estableció que esta prerrogativa tiene carácter fundamental y universal.

La norma de 1886 tampoco dice nada del deber de diligencia a cargo del Estado, lo cual explica que la ralentización en la toma de las decisiones que afectaban a los asociados no ocupara un lugar preponderante en la actividad gubernamental, en lo que por supuesto hay excepciones notables que hacen aún más dramática la reflexión sobre el contenido de la regla general. Si se piensa bien, esa morosidad en la actividad de lo público constituye una particular forma de ejercer violencia respecto de los ciudadanos, la cual, por la línea infinita de tiempo que plantea la narrativa del coronel, tiende a volverse endémica si se expresa en los términos de una patología social:

-Qué te pasa -preguntó. 
-Estoy pensando en el empleado de quien depende la pensión -mintió el coronel-. Dentro de cincuenta años nosotros estaremos tranquilos bajo tierra mientras ese pobre hombre agonizará todos los viernes esperando su jubilación (García Márquez, 2016, p.60).

La muerte de Agustín, "acribillado nueve meses antes en la gallera, por distribuir información clandestina” (García Márquez, 2016, p.18), merece comentario aparte.

A pesar de que desde siempre las ejecuciones sumarias han estado proscritas en el contexto constitucional colombiano ${ }^{11}$, no es de sorprender que tengan espacio en esta novela. Testimonio de ello es que en el contexto vital del coronel sea perfectamente posible que este se encuentre frente a frente con el homicida de su hijo el cual, como si nada hubiese pasado, sigue ejerciendo la condición de agente del Estado.

Artículo 21. - En caso de infracción manifiesta de un precepto constitucional en detrimento de alguna persona, el mandato superior no exime de responsabilidad al agente que lo ejecuta.

Los militares en servicio quedan exceptuados de esta disposición. Respecto de ellos, la responsabilidad recaerá únicamente en el superior que da la orden (Constitución Política de Colombia, 1886).

¿Las violencias concluyen con nuevas violencias?, parece preguntarse García Márquez al reflexionar que solo la vejez le impide al coronel ejercer la venganza por la muerte de su hijo.

La lectura exegética de la norma legal que propone esta historia es por demás francamente desoladora. Dice, sin decirlo, que los homicidios cometidos como actos propios del servicio marchaban inexorable y decisivamente hacia la impunidad. Necesario resulta concluir que en el universo garciamarquiano

\footnotetext{
11 Artículo 19. - Las autoridades de la República están instituidas para proteger a todas las personas residentes en Colombia, en sus vidas, honra y bienes, y asegurar el respeto recíproco de los derechos naturales, previniendo y castigando los delitos (Constitución Política de Colombia, 1886).
} 
la esperanza de alcanzar la armonía social no se sitúa en la aplicación de las normas, fin último del derecho, o por lo menos no en las que estaban vigentes en el contexto temporal en el que transcurre su narrativa.

La Constitución de 1886 rigió en el país hasta el 4 de julio de 1991. A partir del nuevo texto constitucional todos los defectos evidenciados en este apartado fueron corregidos. En consecuencia, la influencia de García Márquez en la construcción del discurso legal se encuentra en proceso de construcción.

En la sentencia C-761 de 2009 la Corte Constitucional colombiana se vale de la historia del coronel para reconocer que las peleas de gallos, al igual que las corridas de toros, hacen parte de la identidad cultural de la nación, esto da un alcance adicional a la narrativa garciamarquiana y la sitúa en la esquina del reconocimiento de algunos de los elementos que constituyen esa afinidad:

En cuanto a las peleas de gallos, parece ser que estas son originarias de la India. Los griegos adoptaron la práctica de desafíos gallísticos y Julio Cesar la introduce a Roma y, por ende, a Hispania. Con Colón llega a América. Colombia ha sido un país de tradición gallística desde la fundación de la República, la cual ha permeado las artes y las letras. En las obras de Gabriel García Márquez la crianza de gallos de pelea y sus riñas han sido una constante como en "Cien Años de Soledad" y, especialmente, en "El Coronel no tiene quien le escriba" (Sentencia C-761 de 2009. Mag. Henao Pérez).

De igual forma, ha servido para justificar posiciones disidentes a las mayoritarias al interior del órgano de cierre de la jurisdicción constitucional colombiana, en lo que se trata del elemento narratológico del tiempo sin fin, del que se vale el autor para ilustrar que con la decisión que adopta la Corte ninguna solución al problema que se analiza llegará para los afectados:

Como corolario no quisiera dejar de señalar que esta clase de interpretaciones regresivas e irracionales están dejando a los empleados y funcionarios públicos del 
Estado en una situación similar a la que nos presentó García Márquez en su célebre novela El Coronel no tiene quien le escriba, en la que su protagonista El coronel (como nuestros trabajadores), espera algo que nunca va a llegar" (Aclaración de voto Mag. Palacio Palacio, a la Sentencia SU-288 de 2015. Mag. González Cuervo).

Las providencias en cita son las únicas dos que, la Corte Constitucional colombiana, desde la creación de hace ya casi tres décadas, se ha valido de esta narrativa para ilustrar el contenido de sus decisiones, lo que no deja de llamar la atención en una sede judicial que anualmente tramita miles de decisiones en materia pensional y muchas más en las que el ciudadano del común reclama un actuar eficiente por parte del Estado.

\subsubsection{Conclusiones}

1. Las lecturas que admite El coronel no tiene quien le escriba son diversas, algunas se han intentado en este escrito:, la inmanencia de la violencia en el contexto sociotemporal en el que se desarrolla la narrativa; el problema de la temporalidad como factor de tensión perpetua en el drama que padecen el coronel y su mujer; la linealidad de la tragedia entendida como la sucesión de calamidades que implacablemente afligen el contexto vital de todos los personajes inmersos en esta historia, entre otras. No obstante, la que implica un contenido de tipo legal agrega un valor novedoso al análisis de esta literatura, en la medida en que permite advertir el tratamiento que desde el punto de vista de las distintas temáticas jurídicas el autor da al contexto constitucional aplicable al momento histórico en el que se desarrolla la temática objeto de su obra.

Así, en esta literatura el derecho adquiere una serie de características relevantes. La primera de ellas es la perfecta armonía que existe entre el contenido literario y el que normativamente resulta aplicable a las distintas situaciones que se narran. A ello se acompaña una interpretación que desde el punto de vista del autor resulta pesimista, y razones no le faltan, pero también exegética, como en parte resulta las más de las veces la 
aplicación de la ley, lo que a su vez nutre el relato porque ayuda a ambientarlo de una manera que a lo menos resulta desoladora.

2. García Márquez ofrece interpretaciones paradójicas pues, contrario a lo que pudiera pensarse en un primer momento, el relato del coronel anónimo es también un canto de esperanza en diversos sentidos de la vida sobre la muerte, de la perseverancia sobre la adversidad y de la justicia sobre la violencia y la arbitrariedad. Los protagonistas genuinamente esperan que lo legal opere y que de alguna forma aparezca para que de ello salga la justicia. "-Así es- suspiro el coronel-. La vida es la cosa mejor que se ha inventado" (García Márquez, 2016, p. 61).

El clamor por el reconocimiento de los derechos de la sociedad termina siendo una expresión de activismo literario, que de hecho el constituyente de 1991 terminó expresando, sin hacer mención al trabajo del Nobel, en las consideraciones que llevaron a la expedición de la Constitución hoy vigente en Colombia, de la siguiente manera:

Para que la vida del hombre sea digna de comienzo a fin, es perentorio asegurarle a la persona de la tercera edad el derecho a la seguridad y el disfrute del bienestar social que incluyen los de salud, la alimentación adecuada y la vivienda. Se habla aquí de seguridad social y de bienestar social antes que de cualquier acto de caridad porque la conmiseración es nociva para el anciano (Lleras de la Fuente, 1996, p. 217).

\subsection{Crónica de una muerte anunciada}

Crónica de una muerte anunciada recoge una serie de acontecimientos ocurridos en 1951 en algún municipio del caribe colombiano. La historia en la que se inspira contó con una serie de desarrollos posteriores, lo que trajo como consecuencia que su proceso de concreción tardara varias décadas en fraguarse, hasta encontrar su año de publicación en 1981.

Respetando las formas de la crónica periodística, en las que el autor recoge fuente a fuente las piezas del relato que compone 
y a las que agrega elementos de la narrativa policial, García Márquez propone una historia que a diferencia de El coronel no tiene quien le escriba si tiene final, se anticipa desde el título mismo de la novela pero que, pese a ello, no hace perder ni por un instante el interés en la cadena de acontecimientos que desembocan en la muerte de Santiago Nasar.

A diferencia de Edipo Rey en el que solo hasta la conclusión el razonador descubre que él mismo es el asesino, en esta crónica nos encontramos ante una especie de subgénero literario: un antipolicial que devela el misterio en el primer párrafo de la primera página, como si de eliminar el suspenso se tratara.

En lo que parece ser una constante en la narrativa garciamarquiana el pueblo en el que se desarrollan los acontecimientos es innominado, acaso por querer proteger la identidad de los protagonistas de la historia, acaso como una forma de expresar que los hechos que se refieren forman parte de la cotidianidad latinoamericana.

En términos de Santiago Gamboa, esta narrativa recoge elementos propios de la tragedia griega en la que los protagonistas parecen sometidos desde un primer momento al capricho de los dioses. Se encuentran sometidos a serie de fuerzas que les resultan irresistibles y terminan por arbitrar sus destinos, sin que haya espacio para suponer que por la simple voluntad pueden escapar de la fatalidad.

Los hermanos Vicario, los asesinos, se ven obligados a cumplir un destino, que es el de lavar la honra de su hermana, matando a Santiago Nasar. Pero ninguno de los dos quiere hacerlo, y, como dice el narrador, «hicieron mucho más de lo que era imaginable para que alguien les impidiera matarlo, y no lo consiguieron» (Gamboa, 2001).

En armonía con ese planteamiento, Crónica de una muerte anunciada se convierte a la vez en una reflexión sobre la torpeza de los personajes, de sus motivaciones, de la manera en la que en determinados contextos se entiende lo correcto, pero mucho más relevante de la forma en la que se ejerce la justicia. 
La poética que construye García Márquez alrededor del drama que se avecina no deja de sorprender y a la vez de impresionar:

"Siempre soñaba con árboles», me dijo Plácida Linero, su madre, evocando 27 años después los pormenores de aquel lunes ingrato. "La semana anterior había soñado que iba solo en un avión de papel de estaño que volaba sin tropezar por entre los almendros", me dijo. Tenía una reputación muy bien ganada de interprete certero de los sueños ajenos, siempre que se los contaran en ayunas, pero no había advertido ningún augurio aciago en esos dos sueños de su hijo, ni en los otros sueños con árboles que él le había contado en las mañanas que precedieron a su muerte (García Márquez, 2014b, p. 9).

El esfuerzo del novelista es inmenso a la hora de enfrentarse con la realidad. En 2007, a sus 85 años de edad Miguel Reyes Palencia publicó un libro titulado Yo soy Bayardo San Román. En declaraciones sobre su obra a la revista Semana, refiriéndose a Margarita Chica, verdadero nombre de Ángela Vicario, señaló: "Así fueron las cosas y no tengo ningún remordimiento", al tiempo que agregó, "Si hubiera sabido que con eso iba a causar la muerte de un amigo, no la devuelvo a su mamá. Yo me hubiera sacrificado por salvarle la vida" (Semana, 13 de octubre de 2007).

El sacrificio del que habla Reyes Palencia hace referencia a convivir con una mujer que no llegó virgen al matrimonio. En ningún momento alude a la posibilidad de interceder por la vida de Cayetano Gentile, el Santiago Nasar de García Márquez.

Destacable de las afirmaciones de Reyes Palencia, el dejar implícito que en el contexto en el que se desarrollaron los hechos la decisión sobre la manera en la que las mujeres ejercían su sexualidad no dependía de ellas sino de la convención social, lo que desde el punto de vista de las lecturas de género que se pueden hacer de la obra, propone un cuestionamiento a la inexistencia que para ese momento tenía en el ordenamiento legal el derecho a la igualdad. 
A diferencia de la manera en la que la narrativa presenta la génesis del amor de Bayardo San Román por Ángela Vicario, la realidad toma distancia simplemente para ratificar el talento creador del escritor:

En cambio, todas las versiones coincidían en que Ángela Vicario y Bayardo San Román se habían visto por primera vez en las fiestas patrias de octubre, durante una verbena de caridad en la que ella estuvo encargada de cantar las rifas. Bayardo San Román llegó a la verbena y fue derecho al mostrador atendido por la rifera lánguida cerrada de luto hasta la empuñadura, y le preguntó cuánto costaba la ortofónica con incrustaciones de nácar que había de ser el atractivo mayor de la feria. Ella le contestó que no estaba para la venta sino para rifar.

-Mejor -dijo él-, así será más fácil, y además, más barata. Ella me confesó que había logrado impresionarla, pero por razones contrarias del amor. "Yo detestaba a los hombres altaneros, y nunca había visto uno con tantas ínfulas -me dijo, evocando aquel día-. Además, pensé que era un polaco". Su contrariedad fue mayor cuando cantó la rifa de la ortofónica, en medio de la ansiedad de todos, y en efecto se la ganó Bayardo San Román. No podía imaginarse que él, sólo por impresionarla, había comprado todos los números de la rifa (García Márquez, 2014b, pp. 34-35).

Reyes Palencia, por su parte, reconoce que su corazón no pertenecía a Margarita Chica, sino a su prima Narcisa Velilla, amor frustrado de la infancia con el que, al igual que ocurre en Cien años de soledad, aconteció que se vio signado por el fracaso debido a la convención familiar de que los amores entre parientes no se pueden dar.

Cuenta en su entrevista, además, que antes de conocer a Margarita, quien a su vez había sido rechazada por Gentile, el tiempo le había alcanzado para tener un romance en Magangué, municipio del departamento de Bolívar ubicado también en la costa caribe colombiana, con Enriqueta Obregón, personaje que no toma para sí la narrativa garciamarquiana. A diferencia de 
lo que ocurre en la novela, los amores de Reyes y Chica son amores cansados, de esos que llegan a la pelea cuando ya va por el noveno asalto, en consecuencia, no pasaron de ser una posibilidad frustrada:

Ambos, despechados, empezaron una relación que duró tres años y que no habría terminado en matrimonio de no ser porque Reyes temió por su vida. "Cuando le dije a Margarita que no quería casarme, ella les dijo a sus hermanos Víctor y Joaquín (los Pedro y Pablo de Gabo), comerciantes y vendedores de carne, que yo la había perjudicado y que estaba embarazada", cuenta Reyes. Enfurecidos, lo habrían amenazado diciéndole que él no podía burlar el honor de la familia Chica Salas, que tenía que casarse o, de lo contrario, lo mataban. "No quiero un hijo soltero y muerto", recuerda Reyes las palabras de su mamá (Semana, 13 de octubre de 2007).

En el contexto de la realidad Margarita Chica obliga al vínculo matrimonial, en la narrativa Ángela Vicario se ve obligada a su celebración por la presión familiar.

Respecto al matrimonio mismo, valga decir el de la literatura y el de la realidad encuentran puntos de sintonía. Mientras Reyes Palencia lo resume diciendo: "Yo preparé un matrimonio de primera categoría" (Semana, 13 de octubre de 2007), García Márquez no escatima esfuerzos en narrar las proporciones casi romanas del evento.

Cristo Bedoya, que estaba con ellos, reveló cifras que aumentaron el asombro. [...] Allí obtuvo muchos datos que le faltaban para calcular los costos de la parranda. Contó que se habían sacrificado cuarenta pavos y once cerdos para los invitados, y cuatro terneras que el novio puso a asar para el pueblo en la plaza pública. Contó que se consumieron 205 cajas de alcoholes de contrabando y casi 2.000 botellas de ron de caña que fueron repartidas entre la muchedumbre. No hubo una sola persona, ni pobre ni rica, que no hubiera participado de algún modo en la parranda de mayor escándalo que se había visto jamás en el pueblo. 
Santiago Nasar soñó en voz alta. -Así será mi matrimonio -dijo-. No les alcanzará la vida para contarlo (García Márquez, 2014b, pp. 23-24).

Preocupado por la negativa de Margarita a tener relaciones sexuales una vez el contrato marital había recibido la bendición sacramental, Reyes insistió en la consumación del vínculo y, ante la negativa de la novel contrayente, con calamitosa contundencia recuerda que atinó a decir: "O lo hacemos o esta vaina se acaba aquí". (Semana, 13 de octubre de 2007).

De ahí en adelante todo fue para peor. En su relato Reyes decide devolverle la contrayente a su madre, quien aguardaba expectante que todo saliera bien en aquella noche infeliz. Después de este particular ejercicio de repudio medieval, natural es pensar que el nombre de Cayetano Gentile saldría a la luz como responsable de la virginidad perdida de Margarita Chica:

Ella se demoró apenas el tiempo necesario para decir el nombre. Lo buscó en las tinieblas, lo encontró a primera vista entre los tantos y tantos nombres confundibles de este mundo y del otro, y lo dejó clavado en la pared con su dardo certero, como a una mariposa sin albedrío cuya sentencia estaba escrita desde siempre.

-Santiago Nasar-dijo (García Márquez, 2014b, pp. 23-24).

El rigor en el relato acompasa la realidad y la ficción. Cayetano Gentile, estudiante de medicina de 24 años de edad, el día en que lo asesinaron los hermanos Chica Salas, tenía un futuro promisorio al igual que su otro yo, Santiago Nasar, dedicado al desarrollo del Divino Rostro, hacienda familiar heredada del padre fallecido tiempo atrás. Según el relato de Reyes Palencia, el cuchillo de matarife que utilizaron para ultimar a Gentile ingresó en el cuerpo en dieciocho oportunidades. Los cuchillos utilizados por los gemelos Vicario lo hicieron en veinticuatro ocasiones cumpliendo el mismo propósito criminal.

García Márquez sitúa los móviles del crimen en el argumento del abogado, que actúa en la causa en la defensa de Pedro y Pablo Vicario: el homicidio se explica por virtud de la 
legítima defensa del honor. Para Reyes Palencia la motivación es más sencilla: "actuaron así porque estaban envenenados. Esos eran otros tiempos" (Semana, 13 de octubre de 2007). En lo que deja claro que en la ira no hay honor.

Al igual que Pedro y Pablo Vicario, Víctor y Joaquín Chica Salas pasaron varios años en una cárcel remota. Y, de la misma forma que en la novela, Margarita Salas, al igual que Ángela Vicario, cambió de pueblo y nunca se casó. Ángela Vicario, por el contrario, tuvo una segunda oportunidad sobre la tierra con Bayardo San Román, en ello la narrativa terminó por enmendar la infelicidad que la persiguió sin tregua.

En su testimonio, Miguel Reyes cuenta que buscó refugiarse en el amor de Enriqueta Obregón. De ese reencuentro hace un esfuerzo notable en beneficio de la concreción: "Yo le pedí perdón y fuimos felices con nuestros 12 hijos. Por mucho tiempo no volví a mencionar lo que me había pasado". Paradójicamente, desde lo legal, era imposible para Reyes casarse con quien terminó siendo su compañera vital porque, a pesar del repudio, nunca se divorció legalmente de Margarita Chica, con quien estuvo unido por el contrato matrimonial hasta el día en que esta falleció.

García Márquez adquiere en este relato una doble condición, no solo la de testigo de oídas a partir de la historia referida por su madre Luisa Santiaga Márquez, como el mismo reconoce en entrevista al diario El País, concedida el 1 de mayo de 1981, sino también que se inserta en el relato como un narrador omnisciente que a pesar de no identificarse da pistas inequívocas sobre su presencia.

Muchos sabían que en la inconsciencia de la parranda le propuse a Mercedes Barcha ${ }^{12}$ que se casara conmigo, cuando apenas había terminado la escuela primaria, tal como ella misma me lo recordó cuando nos casamos catorce años después (García Márquez, 2014b, p. 49).

\footnotetext{
12 Mercedes Barcha Pardo fue la esposa de Gabriel García Márquez desde el 21 de marzo de 1958 hasta el día en que el escritor falleció.
} 


\section{A lo que agrega:}

Mi tía Wenefrida Márquez estaba descamando un sábalo en el patio de su casa al otro lado del río, y lo vio descender las escalinatas del muelle antiguo buscando con paso firme el rumbo de su casa.

-¡Santiago, hijo -le gritó-, ¡qué te pasa!

Santiago Nasar la reconoció.

-Que me mataron, niña Wene -dijo (García Márquez, 2014b, p. 126).

Esta narrativa, a juicio de García Márquez, se constituye en la mejor de sus novelas (Ceberio, 1 de mayo de 1981), y explora desde una perspectiva más íntima el fenómeno de la violencia, una que no por ser doméstica desmerece en su relevancia social. No podía ser distinto, si lo que justamente hace a lo largo del relato es poner magia a la realidad.

\subsubsection{Contexto histórico}

Para 1951 Colombia se encuentra dando curso a una más de sus complejas transiciones políticas. Laureano Gómez (18891965), elegido presidente para el periodo 1950 a 1954 , cesa abruptamente su gobierno por problemas de salud. La sucesión presidencial recayó en Roberto Urdaneta Arbeláez (1890-1972). El 13 de junio de 1953, cuando Gómez, ya repuesto de sus dificultades médicas intenta recuperar el poder termina siendo depuesto en forma definitiva por un golpe de estado liderado por el general Gustavo Rojas Pinilla.

Gómez, admirador del franquismo español y en algunos temas del nazismo alemán, intentó reflejar en su gobierno buena parte de las ideas que componían el credo político de esas organizaciones. No resulta sorpresivo que una visión a ultranza conservadora del Estado se expresara en el ejercicio de la cosa pública y que ello tuviera a su vez diversos correlatos en la sociedad.

En el gobierno Gómez-Urdaneta, denominado así simplemente para enmarcarlo en un periodo de tiempo, el Congreso 
de la República aprobó un acto de convocatoria a una Asamblea Nacional Constituyente que tenía como propósito reformar la Carta Política de 1886. Dicha disposición, aprobada el 9 de diciembre de 1952, devino en un proyecto en el que entre otras cosas "se le asignaba a la prensa la función de servicio público y se establecía que ningún colombiano podía "de palabra o por escrito" atentar contra el prestigio de las autoridades so pena de ser juzgado como traidor" (Alarcón, 18 de mayo de 2015).

Dichas medidas retratan bastante bien el talante autoritario y por demás violento del gobierno de Laureano Gómez, respecto del cual la literatura colombiana se empezó a manifestar, "Jorge Zalamea, Eduardo Caballero Calderón y el mismo Gabriel García Márquez empezaron a plasmar en sus escritos sus inconformismos contra la realidad nacional de ese tiempo. Igualmente, por sus simpatías con la izquierda y con el Partido Liberal, denunciaron en sus obras la persecución que sufría esta última colectividad" (Pardo Motta, 2008, p. 38).

Sobre Laureano Gómez, García Márquez escribió:

A mediados del año llegó a Bogotá el poeta Pablo Neruda, convencido de que la poesía debía ser un arma política. En sus tertulias bogotanas se enteró de la clase de reaccionario que era Laureano Gómez, y a modo de despedida, casi al correr de la pluma escribió en su honor tres sonetos punitivos, cuyo primer cuarteto daba el tono de todos:

Adiós, Laureano nunca laureado,

Sátrapa triste y rey advenedizo.

Adiós, emperador de cuarto piso,

antes de tiempo y sin cesar pagado (Díaz, 2015, p. 101).

A pesar del activismo político de García Márquez en la década del cincuenta es curioso que no se haga ninguna mención en Crónica de una muerte anunciada al estado general de la situación que por esos años vivía el país, en lo que no queda camino distinto que el de ratificar que en esta narrativa el autor no se alejó ni un milímetro de su papel de cronista de los hechos que condujeron a la muerte de Santiago Nasar. 
A diferencia de lo que ocurre en El coronel no tiene quien le escriba, la violencia como objeto de preocupación del escritor se circunscribe a la tragedia que atestiguan los habitantes del pueblito en el que Nasar es asesinado. El ejercicio del poder del Estado a cargo de las autoridades es descrito en el contexto de la narrativa, como un formidable canto a la negligencia:

Muchos de los que estaban en el puerto sabían que a Santiago Nasar lo iban a matar. Don Lázaro Aponte, coronel de academia en uso de buen retiro y alcalde municipal desde hacía once años, le hizo un saludo con los dedos. "Yo tenía mis razones muy reales para creer que ya no corría ningún peligro", me dijo (García Márquez, 2014b, p.25).

\subsubsection{Problemas constitucionales asociados a la obra} y aproximación jurisdiccional

Desde la perspectiva de lo legal, Crónica de una muerte anunciada aparece en una primera lectura, como una obra más próxima al ámbito de estudio del derecho penal que al del constitucional. Los elementos de juicio para confirmar esta primera afirmación, están todos ahí: la premeditación de los gemelos Vicario; la condición a la que fue sometida la víctima cuando fue asesinada; el papel de determinadores del crimen que tienen varios de los personajes de la obra, en la que incitan a los homicidas a ultimar a Santiago Nasar; la sevicia como causal de agravación punitiva (¿si con una cuchillada bastaba para asesinar a la víctima para qué le hicieron veinticuatro?).

De hecho, la misma radiografía que hace el autor respecto del juicio que con jurado de conciencia a bordo llevó a la condena de los Vicario, da testimonio de que esta narrativa es pieza valiosísima para el análisis que desde la mirada de la regulación criminal es posible realizar.

El abogado sustentó la tesis del homicidio en legítima defensa del honor, que fue admitida por el tribunal de conciencia, y los gemelos declararon al final del juicio que hubieran vuelto a hacerlo mil veces por los mismos 
motivos. Fueron ellos quienes vislumbraron el recurso de la defensa desde que se rindieron ante su iglesia pocos minutos después del crimen. Irrumpieron jadeando en la Casa Cural, perseguidos de cerca por un grupo de árabes enardecidos, y pusieron los cuchillos con el acero limpio en la mesa del padre Amador. Ambos estaban exhaustos por el trabajo bárbaro de la muerte, y tenían la ropa y los brazos empapados y la cara embadurnada de sudor y de sangre todavía viva, pero el párroco recordaba la rendición como un acto de gran dignidad.

-Lo matamos a conciencia -dijo Pedro Vicario-, pero somos inocentes.

-Tal vez ante Dios -Dijo el padre Amador.

-Ante Dios y ante los hombres -dijo Pablo Vicario-. Fue un asunto de honor (García Márquez, 2014, p.55).

Sin embargo, desde lo constitucional, objeto de este trabajo, hay problemas implícitos en el capítulo del crimen que conviene examinar, así como otros que se atenderán más adelante.

El primer aspecto, y también el más relevante, consiste en el tratamiento que esta narrativa da al derecho, al debido proceso y a la presunción de inocencia. Pese a que la Carta Política de 1886 incorporaba una regla natural del debido proceso, entendido como el conjunto de garantías con las que cuenta quien habrá de ser enjuiciado, se queda corta a la hora de dotar de garantías el trámite procesal. En efecto, el artículo 26 de dicha norma indicaba que "Nadie podrá ser juzgado sino conforme a leyes preexistentes al acto que se impute, ante Tribunal competente, y observando la plenitud de las formas propias de cada juicio" (Constitución Política de Colombia, 1886) garantía con la que contaron los Vicario, pero no Santiago Nasar.

Fue suficiente la manifestación de Ángela Vicario para que la suerte de Nasar estuviera echada. Nadie preguntó si el dicho de la joven cuya honra se pretendía proteger con su ejecución era cierto o no. No hubo testimonios. No se cotejaron versiones. No reposa en la narrativa ningún rastro que permita suponer la existencia de un romance previo como el que en la trama real 
en efecto existió entre Margarita Chica y Cayetano Gentile. En esencia no hubo nada de nada. En este proceso de facto todas las garantías le fueron negadas a la víctima, quien encontró la muerte a manos de los jueces que en cuestión de horas se convirtieron en sus verdugos, a la vez que en reclamantes de la justicia que al tiempo negaban.

Inevitablemente Santiago Nasar era culpable y estaba muerto desde antes de haber salido de su cama el día que lo mataron. Esta idea justifica la convicción de que Crónica de una muerte anunciada es una narrativa que reflexiona sobre la justicia y la manera en que se ejerce:

Por "justicia", en un sentido más estricto o restringido, puede entenderse al menos tres cosas: en primer lugar, un valor jurídico que preside y está presente en cualquier ordenamiento jurídico; en segundo lugar, una organización jurisdiccional institucionalizada para hacer cumplir el Derecho; y en tercer lugar, una actitud de los juristas en general, que crean, interpretan y aplican el Derecho de acuerdo a ciertos parámetros (Ruiz, s.f., p. 3).

La justicia, vinculada al contexto estrictamente constitucional en cabeza de Santiago Nasar, simplemente devino en nula.

En el entramado legal que construye García Márquez, otras víctimas, ya no desde la mirada de lo penal sino desde la óptica de lo constitucional, aparecen ocupando el primer lugar, entre ellas Ángela Vicario y sus hermanas:

Ellas habían sido educadas para casarse. Sabían bordar con bastidor. Coser a máquina, tejer encaje de bolillo, lavar y planchar, hacer flores artificiales y dulces de fantasía y redactar esquelas de compromiso. [...] Salvo por eso, pensaba que no había hijas mejor educadas. Son perfectas le oía decir con frecuencia-. Cualquier hombre será feliz con ellas, porque han sido criadas para sufrir (García Márquez, 2014, p. 37).

Se destacan ciertas semejanzas de la narrativa que se examina con las descripciones de Gustave Flaubert (1821-1880) sobre el papel de la mujer en Madame Bovary: 
En los primeros tiempos que Charles frecuentaba los Bertaux, su esposa no dejaba de informarse sobre el enfermo, e incluso eligió una bonita página en blanco del libro donde llevaba las cuentas de Monsieur Rouault. Pero cuando se enteró de que éste tenía una hija, buscó informarse; así supo que Mademoiselle Rouault, educada en el convento, con las ursulinas, había recibido, como suele decirse, una buena educación, que, en consecuencia, sabía danza, geografía, dibujo, hacer tapices y tocar el piano (Flaubert, 2014, p. 66).

A lo que agrega:

En cuanto a la mujer del farmacéutico, era la mejor esposa de Normandía, dulce como un cordero, cariñosa con sus hijos, con su padre, con su madre, sus primos, compasiva, ante las desgracias ajenas, eficaz en cuestiones domésticas, y enemiga de los corsés -pero tan lenta para moverse, tan aburrida de escuchar, de una aspecto tan común y de una conversación tan limitada que, jamás pensó, a pesar de ella tuviese treinta años y él veinte, que durmieran a una puerta de distancia, que él le hablara todos los días, que ella pudiese ser la mujer de alguien, o que de su sexo ella tuviera otra cosa más que el vestido (Flaubert, 2014, p. 171).

En contraste, ni una sola sílaba se dice del derecho a la educación de las hermanas Vicario. No hay mayores distinciones en lo demás. Nada se dice, por ejemplo, de la proscripción de su derecho al libre desarrollo de la personalidad, en el que se incluye la elección de la manera en que las mujeres pueden ejercer su sexualidad. Simplemente la vida era así. Es desalentador el elemental cálculo temporal, pues no es mucho lo que va, en lo que a los derechos de género respecta, de lo que ocurría en la provincia francesa del siglo XIX, a lo que acontecía en la Colombia rural del siglo XX. A veces en cien años no es mucho lo que ocurre.

Así, Crónica de una muerte anunciada se convierte en una narrativa eficiente para ilustrar que las temáticas legales, en lo que al género respecta, revelan que las restricciones en 
la vida de las mujeres resultan inversamente proporcionales a las libertades, estas sí sin límites legales o morales, de las que gozaban los hombres para el desarrollo de su personalidad. En realidad, lo que hace García Márquez es adelantarse a su tiempo a la hora de poner de presente la situación de la mujer, en general, y la de la provincia colombiana en particular, tema que solo sería corregido, al menos en la regulación, hasta el ocaso del siglo XX.

El honor de la mujer, considerado como una de sus virtudes más importantes, ha jugado un papel preponderante en su formación en todas las épocas; en el caso colombiano, a las mujeres se les inculcó de que en ellas residía el honor de la familia, el que se vería perjudicado si se dedicaban a llevar una vida sexual libre. El honor debía ir acompañado de la dignidad para poder soportar con decoro el difícil papel que la sociedad patriarcal imponía: soportar en silencio el duro trabajo que implicaba desempeñarse como ama de casa, madre y esposa, sin poder quejarse, soportando la presión que esto traía consigo (Aristizábal, 2005, p.120).

Desde el punto de vista de la jurisprudencia constitucional esta narrativa ha servido para ilustrar distintas cuestiones, principalmente las relativas a la prédica de asuntos que por las características que los preceden, es fácil pronosticar su desafortunado desenlace, de lo que resulta destacable la fortaleza del eje central de la trama.

Como en la novela Crónica de una muerte anunciada de Gabo, "El día en que lo iban a matar"; o mejor, en el que esta Corte mató al Estado de Derecho, me levanté a las 5:30 de la mañana del 2 de julio y el diario El Tiempo decía: "No revisar sentencia que validó la reelección propone ponencia que estudia la Corte Constitucional". "Según Fuentes consultadas por EL TIEMPO, en el tribunal predomina la premisa de que sus sentencias hacen tránsito directo a cosa juzgada sin posibilidad de revisión". Era obvio que el proyecto del Magistrado Escobar y la decisión se habían filtrado; y que los medios 
conocían no sólo el sentido de la ponencia que se presentó a Sala Plena, sino la posición que adoptaría la mayoría de los Magistrados de esta Corte, situación que en concepto del suscrito magistrado no sólo atenta, sino que vulnera la dignidad, credibilidad y legitimidad de esta Corporación (Salvamento de voto del Mag. Araújo Rentería, al Auto 1658 de 2008. Decisión de Sala Plena del 2 de julio de 2008).

Lo afirmado es destacable, en tanto en el imaginario colectivo la utilización del poder de la narrativa garciamarquiana refiere inevitablemente a la fatalidad, lo cual en la construcción del diálogo legal se establece como una potente herramienta cuando el ciudadano acude en busca de ganarse el ánimo del juez en favor de la causa que alega, como se aprecia continuación:

Encuentra afectada la actividad laboral porque se abstendrán de venir a Colombia los circos con animales, que son generadores de empleo, aparte de ser el trampolín para perfeccionar el arte de los artistas colombianos. Recuerda que no son solo domadores los que trabajan en los circos, también hay payasos, equilibristas, malabaristas, magos, contorsionistas, vendedores, acomodadores, personal de planta, logística, electricistas, carpistas, entre otros, por lo que la falta de oportunidad para el circo tradicional generaría más que una Crónica de una muerte anunciada. Entiende que las leyes están para proteger a las minorías. La recreación y la cultura han sido ignoradas por un Estado que dice ser social de derecho, sin tener en cuenta que el circo en Colombia es el único espectáculo cultural que llega a los lugares más recónditos del país (Intervención ciudadana del señor Pedro Alfonso López. Sentencia C-283 de 2014 Mag. Palacio Palacio).

La construcción literaria inmersa en Crónica de una muerte anunciada se asocia indisolublemente a la violencia adherida, desde siempre, a la historia de Colombia. La manera en la que ello se expresa en el discurso legal hace pensar que la sola invocación de su nombre convierte cualquier situación en una premonición de la tragedia. 
El tema anterior se encuentra íntimamente ligado al fracaso de los organismos de inteligencia del estado, ya que el hombre de la calle no entiende como cualquier periodista o candidato presidencial (recuérdese el caso de Pastrana cuando aspiraba a la presidencia y se entrevistó con el jefe de un grupo subversivo, al margen de la ley), saben dónde ellos están, llega hasta donde ellos están y sin embargo, los cientos de miembros de los órganos de inteligencia desconocen su paradero. ¿Qué ley o norma constitucional impide que los organismos de inteligencia descubran el paradero de los cabecillas de esos grupos y que luego la fuerza pública los capture? Este fracaso es patético, en el caso de los hechos del 7 de agosto, pues parodiando a nuestro premio Nobel (Crónica de una muerte anunciada), se ejecutó un ataque anunciado, se desplegaron cerca de 20.000 hombres para contrarrestarlo y sin embargo se realizó y este fracaso de los órganos de inteligencia no puede cobrársele a los ciudadanos limitándoles sus derechos humanos. Quien debe pagar el error son los responsables de los órganos de inteligencia, separándoles de sus cargos y no los ciudadanos que no lo cometieron. El propio decreto de conmoción reconoce, y confiesa, que los servicios de inteligencia no son efectivos (p. 3 del decreto. Sentencia C-802 de 2002. Mag. Córdoba Triviño).

$\mathrm{Al}$ igual que ocurre en la narrativa, la realidad se acompasa con la ficción y en ese orden de ideas, el discurso legal para ilustrar lo previsible que resultaba a los aparatos de seguridad del Estado el accionar terrorista, se acude entonces a la condición universal del texto con el fin de demostrar la irresistibilidad de lo nefasto.

El juez en su decisión parece decir que todos en el pueblo sabían que iban a matar a Santiago Nasar, luego todos, en el contexto de la decisión en cita, sabían que en un país que se encontraba en ese momento en medio de un conflicto armado, debían estar preparados para que el día de la posesión presidencial los grupos armados al margen de la ley adelantaran algún tipo de acto de terror. En otras palabras: todos deben saber que en contextos de violencia lo que puede salir mal saldrá peor. 
Nótese que nuevamente en el discurso judicial, pese a los esfuerzos estatales documentados en la providencia, como en los intentos por desarmar a los Vicario que se describen en la novela media, está presente la noción de la imposibilidad de evitar lo inevitable.

Como se aprecia en las tres decisiones judiciales en cita, la apelación al contenido literario de Crónica de una muerte anunciada se signa por la idea de que el resultado trágico es ineludible, lo que a su vez remite a concluir que esta narrativa, por la fortaleza de su contenido, se afincó en el imaginario social al implicar el ámbito de lo judicial. En una especie de Edipo moderno, no es posible escapar del designio divino cuando los dioses se empeñan en dispensar la tragedia.

\subsubsection{Conclusiones}

1. Crónica de una muerte anunciada se construye sobre la idea de que el derecho y la justicia son una misma cosa y que al ser ello una verdad indiscutible, van de la mano. El acto justo, fundado o no en la razón, confiere en el imaginario la posibilidad de ejercer derechos que nadie ha adjudicado, sin importar que desde la perspectiva estrictamente jurídica lo que se considera éticamente permisible se lleve por delante el sistema de garantías de las que gozan, aun quienes presuntamente incurren en la violación que se pretende castigar.

El mundo de los Vicario, en términos de lego, de buenos y malos es: quien se roba el honor debe ser castigado, el que lo restituye merece redención.

El de la víctima, Nasar, es de grises: resulta ejecutado sin haber sido hallado culpable por la falta que se le imputa; en lo que la influencia kafkiana derivada de $E l$ proceso se convierte en referencia obligada. Al final Josef $\mathrm{K}$. es cualquiera que sea víctima de un atropello en el que, en la condición de acusado sea objeto de la justicia formal o, de hecho, en detrimento de las garantías razonadas y razonables que el ordenamiento jurídico otorga a todos por igual. 
2. Las miradas que se pueden derivar de las problemáticas de género inmersas en Crónica de una muerte anunciada trascienden de lejos, y por mucho, el predicado simple de que esta narrativa es una exaltación del machismo. Por el contrario, si bien es cierto que hasta en las nominaciones las mujeres garciamarquianas son poéticas (Ángela, Divina Flor) y a ello se atribuye en parte su debilidad, el panorama que desde el punto de vista de igualdad se ofrece es tan desolador que no queda más que reivindicar el derecho de las mujeres a desarrollar su personalidad. La tragedia de Ángela Vicario es la de la sanción moral signada por la virginidad perdida que más de medio siglo después no reconoce fronteras ni contextos sociales.

De hecho, las deficiencias del ordenamiento vigente de la Constitución de 1886, trata de corregirlas el constituyente de 1991 con un artículo del siguiente tenor aún en vías de apropiación social:

Artículo 13.- Todas las personas nacen libres e iguales ante la ley, recibirán la misma protección y trato de las autoridades y gozarán de los mismos derechos, libertades y oportunidades sin ninguna discriminación por razones de sexo, raza, origen nacional o familiar, lengua, religión, opinión política o filosófica. El Estado promoverá las condiciones para que la igualdad sea real y efectiva y adoptará medidas en favor de grupos discriminados o marginados.

[...] (Constitución Política de Colombia de 1991).

En armonía con lo anotado por Antonio Cancino en el apartado anterior, García Márquez litiga en todas las causas. En este caso desborda argumentos en favor del reconocimiento de la mujer no solo en cuanto a derechos, también en cuanto a existencia, dignidad y realidad, lo que no resulta menor si se considera que la equidad de género en el mundo es una obra en construcción.

\section{Conclusiones finales}

En carta dirigida a Francisco Navarro Ledesma (1869-1905) Ángel Ganivet (1865-1898) sentencia que "el Abogado, por el 
hecho de serlo, es una bestia nociva para el Arte" (Ossorio, 2007, p. 127). Pareciera que a pesar de la evidencia que prueba la intersección que existe entre derecho y literatura, abrumadora, por cierto, el jurista que se precie de serlo se encuentra condenado a morir con el alma pegada al vericueto de un inciso cuando en realidad tal desperdicio es por demás innecesario:

¿Novela? ¿Versos? Sí. Novela y versos. Esa es la gimnástica del sentimiento y del lenguaje. Se puede vivir sin mover los brazos ni las piernas, pero a los pocos años de tan singular sistema los músculos estarán atrofiados y el hombre será un guiñapo. Pues lo mismo ocurre con el orden mental. La falta de lectura que excite la imaginación, amplíe el horizonte ideal y mantenga viva la renovada flexibilidad del lenguaje, acaba por dejar al Abogado muerto en sus partes más nobles, y le reduce a una ley de Enjuiciamiento con figura humana, a un curialete con título académico (Ossorio, 2007, p. 137).

El argumento de Ángel Ossorio (1873-1946), expresado hace ya casi cien años, apunta a una primera conclusión que a efectos de este ejercicio se torna definitiva: el derecho por sí solo no basta. No resulta suficiente para explicarse a sí mismo. Necesita de la literatura para hacerse comprender y para interactuar de mejor manera con la sociedad cuyas actuaciones, activas o pasivas, pretende regular.

En consecuencia, la narrativa se convierte en un recurso especialmente valioso para construir el discurso legal, bien porque es instrumental al propósito pedagógico que por su naturaleza entraña la decisión judicial, bien porque nutre el contenido de la misma desde lo sustancial, permitiendo que la argumentación jurídica que en ella se expresa se fortalezca con elementos que trascienden en ocasiones la sobrevaluada órbita de lo técnico.

La narrativa garciamarquiana, expresada en Crónica de una muerte anunciada y El coronel no tiene quien le escriba, facilita de forma determinante el diálogo entre los mundos jurídico y literario, no solo porque de la mano del realismo mágico 
habilita una suerte de realismo jurídico que se expresa en la observancia de las reglas de lo legal que resultan aplicables al contexto en el que dichas tramas se desarrollan, sino porque al encontrarse engastadas en el alma colectiva, ilustran, y en eso su sola mención resulta suficiente, la fatalidad propia de los contextos en los que la justicia deviene en nula, por lo menos en lo que al contexto colombiano se refiere, sea porque no llega, sea porque al ser tomada por mano propia es causa eficiente de la tragedia.

Si bien desde el punto de vista académico no se aprecia sustento para afirmar que las novelas de García Márquez influyeron en el ánimo de los constituyentes de 1991, resulta evidente que muchos de los defectos históricos denunciados en estas narrativas fueron objeto de preocupación para los responsables de componer, metafóricamente hablando, la partitura constitucional del país, al punto que no existe, y ello sí es comprobable, aspecto denunciado por el autor en su obra que no encontrara remedio normativo en el texto fundamental en lo que convierte a esta literatura, en términos de Magris, en una visión "innovadora, conmovedora y amenazadora [de la] persecución entre la vida y la ley" (Magris, 2008, p. 61).

No deja de sorprender que veintisiete años después de creada la Corte Constitucional colombiana, la narrativa garciamarquiana referida principalmente a dos de sus novelas más notables sea tan escasamente citada. Cinco casos en total, entre miles y miles en los que se discuten derechos pensionales, al debido proceso, a la presunción de inocencia y a la igualdad dan testimonio de que la jurisprudencia colombiana, a diferencia de la definición de "Jhering "obra de arte, ella crea, inventa, organiza" (Magris, 2008, p. 61), en el sentido que se examina desafortunadamente se queda corta.

Peter Häberle (1934), uno de los juristas más relevantes en el ámbito de la teoría constitucional contemporánea sostiene:

La literatura como tal conlleva una buena parte de corresponsabilidad en los procesos culturales que configuran el Estado constitucional, sea cual fuere la forma 
en la que se manifieste; es decir, ya sea admitiéndolos unánimemente o contradiciéndolos, con sus críticas, o provocando incluso hasta su propio rechazo, con reflexiones generales o con retazos de utopía en concreto, y todo ello cuando menos o tan solo en parte a través de una actitud de oposición fundamental al sistema, cuando dicho "sistema" sea un ordenamiento de las libertades. Justamente porque el Estado constitucional carece de recurso alguno para forzar su aprobación es por lo que se halla en situación de dependencia a largo plazo también de la "libre aprobación" de sus literatos (Häberle, 2000, p. 57).

En otras palabras, lo que Häberle sostiene es que la manera en la que se narran los textos fundamentales en cada sociedad permite apreciar los valores en que se sustentan resumiendo el contenido del alma colectiva en momentos históricos concretos. Al tiempo enseña que la actitud de oposición al sistema complementa el proceso de construcción del texto legal introduciendo contenidos que, en ocasiones particulares, contribuyen a mejorar la sociedad.

En el caso colombiano la norma fundamental de 1991 señala en su preámbulo:

En ejercicio de su poder soberano, representado por sus delegatarios a la Asamblea Nacional Constituyente, invocando la protección de Dios, y con el fin de fortalecer la unidad de la Nación y asegurar a sus integrantes la vida, la convivencia, el trabajo, la justicia, la igualdad, el conocimiento, la libertad y la paz, dentro de un marco jurídico, democrático y participativo que garantice un orden político, económico y social justo, [...] (Constitución Política de Colombia, 1991).

Si se mira bien, el texto en cita no hace nada distinto que recoger el clamor que en las narrativas comentadas pregona García Márquez: El derecho a la vida que se les arrebata a Santiago Nasar y a Agustín, hijo del coronel, víctimas noveladas de la inveterada violencia local. La convivencia fracturada en el 
pueblo anónimo, en el que expresar pensamientos disidentes se castiga con la pena formal de prisión o con la no reglada muerte y en la que ir al cine es casi un acto de sedición. La igualdad proscrita para las mujeres por cuenta de la fuerza de las costumbres y de los prejuicios ancestrales. Y por supuesto la justicia, para que no sea necesario avanzar en la enumeración de los fines perseguidos por la poética constitucional, que se extraña por su ausencia desde la primera hasta la última hoja de estas narrativas breves que terminan por ser a cuenta de esta circunstancia: interpretaciones jurídicas de la realidad.

\section{Referencias bibliográficas}

Alarcón, O. (18 de mayo de 2015). Las constituyentes. El Espectador. Recuperado de https://www.elespectador.com/opinion/ las-constituyentes-columna-561212.

Alemany, C. (2009). La narrativa de la alteridad en América Latina (a partir del boom). Sevilla: ArCiBel.

Aristizábal, P. (2005). Panorama de la narrativa femenina en Colombia en el siglo XX. Cali. Universidad del Valle.

Bunge, M. (1960). Filosofar científicamente y encarar la ciencia filosóficamente. Recuperado de http://fisica.ciencias.uchile. $\mathrm{cl}$ / gonzalo/uploads/Docencia/Bunge_ciencia.pdf.

Cancino Moreno, A. J., Cancino González, I. \& Teleki, J. D. (2005). El Derecho Penal en Macondo. Bogotá: Librería Ediciones del Profesional, Academia Colombiana de la Abogacía, Universidad Externado de Colombia, Colegio de Abogados Penalistas de Bogotá y Cundinamarca.

Ceberio, J. (1 de mayo de 1981). Crónica de una muerte anunciada es mi mejor novela. Recuperado de https://elpais.com/ diario/1981/05/01/cultura/357516008_850215.html.

Díaz, Á. (2015) Gabriel García Márquez: Cien años de eternidad. Madrid: Verbum.

Fuentes, C. (1993). Geografía de la novela. México. Alfaguara.

Flaubert, G. (2014). Madame Bovary, Costumbres de Provincia. Buenos Aires: Eterna Cadencia. 
Gamboa, S. (2001). Prólogo. En García Márquez, G. (2001), Crónica de una muerte anunciada. Madrid, España: El Mundo. Recuperado de http://biblio3.url.edu.gt/Libros/cromuerte.pdf García, L. \& De Fazio, F. (2015). 'Teoría pura del derecho', de Hans Kelsen. Recuperado de https://www.ambitojuridico.com/ administrativo-y-contratacion/teoria-pura-del-derecho-dehans-kelsen

García Márquez, G. (2002). Vivir para contarla. Barcelona. Penguim Random House.

García Márquez, G. (2007). Cien años de soledad. Bogotá: Norma.

García Márquez, G. (2014a). El amor en los tiempos del cólera. Colombia. Penguim Random House.

García Márquez, G. (2014b). Crónica de una muerte anunciada. Colombia. Penguim Random House.

García Márquez, G. (2016). El coronel no tiene quien le escriba. Colombia: Penguim Random House.

Häberle, P. (2000). Teoría de la Constitución como ciencia de la cultura. Madrid: Tecnos.

Kant, I. (2002). La metafísica de las costumbres. Madrid: Tecnos.

Kelsen, H. (1960). Teoría Pura del Derecho. Buenos Aires: Editorial Universitaria de Buenos Aires, Universidad de Buenos Aires.

Liévano Aguirre, I. (2002). Los grandes conflictos sociales y económicos de nuestra historia. Bogotá: Intermedio Editores.

Lleras de la Fuente, C. \& Tangarife, M. (1996). Constitución Política de Colombia, Origen, Evolución y Vigencia. Bogotá: Dike.

Magris, C. (2008). Literatura y derecho ante la ley. México: Sexto Piso.

Mari, E. E. (2015). Derecho y Literatura. Algo de lo que se puede hablar pero en voz baja. En Roggero, Jorge (compilador). Derecho y Literatura. Textos y Contextos. Buenos Aires. Facultad de Derecho Universidad de Buenos Aires, Eudeba.

Mendoza, P. (1982). El olor de la guayaba, Conversaciones con Gabriel García Márquez. Bogotá: La Oveja Negra.

Narváez, J. R. (2017). Derecho y literatura. Una alianza que subvierte el orden. México: Universidad Nacional Autónoma de México.

Ossorio, A. (2007). El alma de la toga. Valladolid: Maxtor 
Oxford University Press. (2018). Oxford Dictionaries. Recuperado de https://www.oxforddictionaries.com/

Pardo Motta, D. (2008). Laureano Gómez y su proyecto de reforma constitucional (1951-1953). Bogotá: Universidad del Rosario.

Pardo Rueda, R. (2004). La historia de las guerras. Bogotá: Ediciones B. Colombia S.A., para el sello Javier Vergara Editor.

Piedrahita, C. R. (1995) Constituciones Politicas Nacionales de Colombia. Bogotá: Instituto de Estudios Constitucionales Carlos Restrepo Piedrahíta, Universidad Externado de Colombia.

Rama, Á. (2005). El boom en perspectiva. Signos Literarios 1. Recuperado de http://signosliterarios.izt.uam.mx/index.php/SLIT/ article/download/807/776

Ruiz, M. (s.f.) El mito de la justicia: entre dioses y humanos. Recuperado de http://www.uv.es/cefd/11/ruiz.pdf.

Real Academia Española. (2011). Diccionario de la lengua española.

Revista Semana (13 de octubre, 2007). Yo me llamo Bayardo San Román. Entrevista a Miguel Reyes Palencia. Revista Semana 1328. Recuperado de https://www.semana.com/gente/ articulo/la-verdadera-historia/88772-3

White, J. B. (2015). Derecho y Literatura: Un no manifiesto. En Roggero, J. (compilador). Derecho y Literatura. Textos y Contextos. Buenos Aires. Facultad de Derecho Universidad de Buenos Aires, Eudeba.

Sófocles. (2014). Antígona. Recuperado de https://dramaticas.una. edu.ar/assets/files/file/artes-dramaticas/2014/2014-ad-unacpu-2015-texto-antigona-sofocles.pdf

Soto Hoyos, J. F. (2014) Jurisprudencia literaria en Colombia: los usos de la literatura en las decisiones judiciales. Revista Summa Iuris, (2) (2) 217 a 251.

Vargas Llosa, M. (1971). García Márquez: historia de un deicidio. Barcelona: Barral Editores.

\section{Providencias Judiciales en cita}

República de Colombia. Consejo de Estado. Sala de lo Contencioso Administrativo, Sección Segunda. Sentencia del 26 de marzo de 1998. Consejero Ponente. Orjuela Góngora. 
República de Colombia. Corte Constitucional. Sentencia C-761 de 2009. Mag. Henao Pérez.

República de Colombia, Corte Constitucional. Salvamento de voto del Mag. Araújo Rentería, al Auto 1658 de 2008. Decisión de Sala Plena del 2 de julio de 2008.

República de Colombia, Corte Constitucional. Aclaración de voto Mag. Palacio Palacio. Sentencia SU-288 de 2015. Mag. González Cuervo.

República de Colombia, Corte Constitucional. Intervención ciudadana del señor Pedro Alfonso López. Sentencia C-283 de 2014 Mag. Palacio Palacio.

República de Colombia, Corte Constitucional. Sentencia C-802 de 2002. Mag. Córdoba Triviño.

\section{Normas en cita.}

1. Constitución Política de Colombia 1886.

2. Constitución Política de Colombia 1991.

3. Código Civil colombiano, ley 57 de 1887. 